OPEN ACCESS

Edited by:

Juan Anguita,

Center for Cooperative Research in

Biosciences, Spain

Reviewed by:

Hiro Goto,

University of São Paulo, Brazil

Jue Hou,

Virginia Mason Medical Center

United States

*Correspondence:

Patricia Sampaio Tavares Veras patricia.veras@fiocruz.br

Specialty section:

This article was submitted to Molecular Innate Immunity,

a section of the journal

Frontiers in Immunology

Received: 17 March 2019 Accepted: 29 May 2019

Published: 28 June 2019

Citation:

de Menezes JPB, Khouri R, Oliveira CVS, Petersen ALdOA, de Almeida TF, Mendes FRL, Rebouças AdAD, Lorentz AL, Luz NF, Lima JB, Ramos PIP, Soares RP, Rugani JN, Buck GA, Krieger MA, Marchini FK, Vivarini ÁdC, Lopes UG, Borges VM and Veras PST

(2019) Proteomic Analysis Reveals a

Predominant NFE2L2 (NRF2)

Signature in Canonical Pathway and

Upstream Regulator Analysis of Leishmania-Infected Macrophages.

Front. Immunol. 10:1362.

doi: 10.3389/fimmu.2019.01362

\section{Proteomic Analysis Reveals a Predominant NFE2L2 (NRF2) Signature in Canonical Pathway and Upstream Regulator Analysis of Leishmania-Infected Macrophages}

\begin{abstract}
Juliana Perrone Bezerra de Menezes ${ }^{1}$, Ricardo Khouri ${ }^{2,3}$, Camila Victoria Sousa Oliveira ${ }^{1}$, Antonio Luis de Oliveira Almeida Petersen ${ }^{1}$, Tais Fontoura de Almeida ${ }^{1,4}$, Flávia R. L. Mendes ${ }^{1}$, Amanda do Amor Divino Rebouças ${ }^{1}$, Amanda Lopes Lorentz ${ }^{1}$, Nívea Farias Luz ${ }^{5}$, Jonilson Berlink Lima ${ }^{6}$, Pablo Ivan Pereira Ramos ${ }^{7}$, Rodrigo Pedro Soares ${ }^{8}$, Jeronimo Nunes Rugani ${ }^{8}$, Gregory A. Buck ${ }^{9}$, Marco Aurélio Krieger ${ }^{10}$, Fabrício Klerynton Marchini ${ }^{10}$, Áislan de Carvalho Vivarini ${ }^{11}$, Ulisses Gazos Lopes ${ }^{11}$, Valéria de Matos Borges ${ }^{2}$ and Patricia Sampaio Tavares Veras ${ }^{1,12 *}$

${ }^{1}$ Laboratory of Host-Parasite Interaction and Epidemiology, Gonçalo Moniz Institute, Fiocruz-Bahia, Salvador, Brazil, ${ }^{2}$ Laboratory of Vector Born Infectious Diseases, Gonçalo Moniz Institute, Salvador, Brazil, ${ }^{3}$ Department of Pathology and Legal Medicine, Faculty of Medicine, Federal University of Bahia, Salvador, Brazil, ${ }^{4}$ Laboratory of Physiopathology, Federal University of Rio de Janeiro, Macaé, Brazil, ${ }^{5}$ Laboratory of Inflammation and Biomarkers, Gonçalo Moniz Institute, Salvador, Brazil, ${ }^{6}$ Centro de Ciências Biológicas e da Saúde, Federal University of the Western of Bahia, Barreiras, Brazil, ${ }^{7}$ Center for Data and Knowledge Integration for Health, Gonçalo Moniz Institute, Fiocruz-Bahia, Salvador, Brazil, ${ }^{8}$ René Rachou Institute, Fiocruz-Minas Gerais, Belo Horizonte, Brazil, ${ }^{9}$ Department of Microbiology and Immunology, Virginia Commonwealth University, Richmond, VA, United States, ${ }^{10}$ Carlos Chagas Institute, Fiocruz-Paraná, Paraná, Brazil, ${ }^{11}$ Laboratory of Molecular Parasitology, Center of Health Science, Carlos Chagas Filho Biophysics Institute, Federal University of Rio de Janeiro, Rio de Janeiro, Brazil, ${ }^{12}$ National Institute of Science and Technology of Tropical Disease, Patos, Brazil
\end{abstract}

CBA mice macrophages (MØ) control infection by Leishmania major and are susceptive to Leishmania amazonensis, suggesting that both parasite species induce distinct responses that play important roles in infection outcome. To evaluate the $M \varnothing$ responses to infection arising from these two Leishmania species, a proteomic study using a Multidimensional Protein Identification Technology (MudPIT) approach with liquid chromatography tandem mass spectrometry (LC-MS/MS) was carried out on CBA mice bone-marrow MØ (BMMØ). Following SEQUEST analysis, which revealed 2,838 proteins detected in BMM $\varnothing$, data mining approach found six proteins significantly associated with the tested conditions. To investigate their biological significance, enrichment analysis was performed using Ingenuity Pathway Analysis (IPA). A three steps IPA approach revealed 4 Canonical Pathways (CP) and 7 Upstream Transcriptional Factors (UTFs) strongly associated with the infection process. NRF2 signatures were present in both CPs and UTFs pathways. Proteins involved in iron metabolism, such as heme oxigenase $1(\mathrm{HO}-1)$ and ferritin besides sequestosome (SQSMT1 or p62) were found in the NRF2 CPs and the NRF2 UTFs. Differences in the involvement of iron metabolism pathway in Leishmania infection was revealed by the presence of $\mathrm{HO}-1$ and ferritin. Noteworty, $\mathrm{HO}-1$ was strongly associated with $L$. amazonensis infection, while ferritin was regulated by both species. As expected, higher $\mathrm{HO}-1$ and p62 expressions were validated in 
L. amazonensis-infected BMM $\varnothing$, in addition to decreased expression of ferritin and nitric oxide production. Moreover, BMM $\varnothing$ incubated with $L$. amazonensis LPG also expressed higher levels of $\mathrm{HO}-1$ in comparison to those stimulated with L. major LPG. In addition, L. amazonensis-induced uptake of holoTf was higher than that induced by L. major in BMMØ, and holoTf was also detected at higher levels in vacuoles induced by $L$. amazonensis. Taken together, these findings indicate that NRF2 pathway activation and increased $\mathrm{HO}-1$ production, together with higher levels of holoTf uptake, may promote permissiveness to $L$. amazonensis infection. In this context, differences in protein signatures triggered in the host by $L$. amazonensis and $L$. major infection could drive the outcomes in distinct clinical forms of leishmaniasis.

Keywords: Leishmania, macrophage, NRF2, CBA mice, iron metabolism

\section{INTRODUCTION}

Experimental murine models have been used to elucidate mechanisms related to host immunity that regulate disease development. CBA mice develop a controlled disease in response to $L$. major infection, while this same mouse strain, in response to L. amazonensis, evolves to a severe form of disease with parasite dissemination (1). Macrophages are crucially important in the response to Leishmania infection, since these cells are not only considered as the primary host cell for Leishmania parasites, but also secrete cytokines in the assembling of an inflammatory response and release chemokines to recruit other immune cells to the site of infection or inflammation. CBA mouse $\mathrm{M} \varnothing$ are capable of containing L. major parasite growth yet are susceptible to L. amazonensis (2). The CBA murine model of experimental leishmaniasis has shed light on several aspects of Leishmania-host interaction, as well as facilitated the identification of important immunoinflammatory molecules differentially produced in response to various parasite species despite their static genetic background.

Proteomics is an advanced large-scale technique used to identify and characterize global protein expression, allowing for the targeting of molecules in an infected sample in comparison to an uninfected reference control, both in intracellular microbes and host cells. This advanced technology has proven to be highly efficient in the study of individual molecules, as it permits the identification of hundreds or even thousands of signature proteins that characterize elements of microbial and host response during infection $(1,3-5)$. In the context of this large-scale analysis, bioinformatics contributes through the use of advanced computational algorithms to search databases [revised by Veras et al. (6)]. Several studies have demonstrated the power of proteomics with respect to providing valuable information regarding the identification of proteins and pathways involved in host-parasite interactions, both in parasites (7-10) as well as in the host $(11,12)$. More importantly, convincing evidence has been presented regarding the involvement of these identified molecules and pathways in the pathogenesis of leishmaniasis. In addition, some proteins have demonstrated potential as possible biomarkers for future prophylactic and therapeutic interventions $(11,13)$.
In intracellular microbial infections, the host oxidative stress response orchestrates the production of cytoprotective molecules, which can influence infection outcome (14). This cytoprotective process induces the activation of the cellular nuclear factor erythroid 2-related factor 2 (NRF2) encoded by the nfe 212 gene, a transcription factor responsible for the regulation of host cellular redox balance $(15,16)$. Activated NRF2 binds to the consensus sequence of the antioxidant response element (ARE), which results in the transcription of a variety of genes, including glutamate-cysteine ligase (GCL), thioredoxin reductase 1 (Txnrd1), and $\mathrm{NAD}(\mathrm{P}) \mathrm{H}$-qui-None oxidoreductase 1 (NQO1). This cytoprotective system is activated by the transcription of NRF2-mediated genes involved in iron metabolism, such as heme oxygenase-1 (HO-1) and the iron storage protein ferritin (17). HO-1, an essential enzyme involved in heme catabolism, as well as in the suppression of inflammatory responses, is induced in response to cellular stress and tissue damage. Oxidative stress activates the transcription factor NRF2, which binds to ARE, inducing the expression of protective antioxidant genes, including HO-1 (18-21). Previously, the major parasite surface glycoconjugate, lipophosphoglycan (LPG) was incriminated in HO-1 induction by parasite species that cause visceral leishmaniasis, Leishmania infantum (19). Recently, the ARE/NRF2 signaling pathway was found to be significantly upregulated in patients with cutaneous leishmaniasis (22). Since, some of those mechanisms are still unknown, use of the dichotomic model of CBA BMMØs infected by L. amazonensis and L. major (2) seems an interesting tool to clarify these issues.

Since iron is central to several metabolic processes for both prokaryotic and eukaryotic cells, iron homeostasis plays a major role in host-pathogen interaction (23-26). Accordingly, the ability of iron to transfer electrons necessary for metabolic processes results in the formation of highly reactive radicals by catalysis $(27,28)$. These radicals can act as signaling molecules in host cells, but can alternatively cause microbial intoxication, thereby damaging surrounding cells and tissues. In response to microbial infection, iron can act directly by imparting synergism toward the formation of anti-microbial radicals (27-30), or indirectly by modulating immune cell anti-microbial effector pathways (24). The latter type of response can result in reduced iron availability for microbes, and is dependent on the host 
cell response to cytokines that regulate the control of pathogen growth and establish an immune effector response (31).

Susceptibility to L. amazonensis has been demonstrated in CBA mice, in opposition to what was seen under L. major infection in vivo (1). In addition, CBA mouse $\mathrm{M} \emptyset$, which were found to be permissive to L. amazonensis in vitro, were observed to mitigate L. major infection (2). The present report employed proteomic analysis to determine the global macrophage response to Leishmania infection by comparing the differentially expressed proteins in CBA BMM $\varnothing$ infected or not with L. amazonensis or L. major. We hypothesized that protein signatures for BMMØ infected with either of these Leishmania strains would provide evidence regarding the proteins involved in infection development or control. Also, some functional experiments regarding iron metabolism were performed.

\section{METHODS}

\section{Ethics Statement}

The CBA mice used in the present study were provided by the animal care facility at the Gonçalo Moniz Institute Fiocruz - Bahia, following approval by the Institutional Animal Experimentation Review Board (CEUA) under protocol number $005 / 2014$. Animals were kept and handled in accordance with the norms recommended by the International Guiding Principles for Biomedical Research Involving Animals; all experimental protocols complied with these guidelines, as well as all resolutions established by the Brazilian National Council for the Control of Animal Experimentation (CONCEA).

All protocols, analytic methods and material used in the present study are available upon request to all interested researchers.

\section{BMMØ Differentiation and Culturing}

Mouse bone marrow macrophage precursors were harvested from CBA mice, differentiated into BMM $\varnothing$, seeded onto 24well plates ( $1 \mathrm{ml}$ of $5 \times 10^{6} / \mathrm{ml}$ suspension) $24 \mathrm{~h}$ prior to experimentation, and incubated in macrophage differentiation media (RPMI 20\% FBS, 30\% L cell-conditioned supernatant, $25 \mathrm{mM}$ HEPES, $2 \mathrm{~g} / \mathrm{L}$ sodium bicarbonate, $200 \mathrm{mM}$ glutamine, and $1 \%$ ciprofloxacin) at $37^{\circ} \mathrm{C} / 5 \% \mathrm{CO}_{2}$. In brief, bone marrow from mouse femurs and tibias were flushed into RPMI 20\% FBS media, cells were centrifuged and then seeded in Petri dishes overnight. The supernatant of these cells was then centrifuged at $300 \times \mathrm{g}$ for $10 \mathrm{~min}$ at $4^{\circ} \mathrm{C}$, resuspended in media containing $30 \% \mathrm{~L}$ cell-conditioned supernatant and transferred to new plates for 7 days. For harvesting, cultures were incubated with $5 \mathrm{mM}$ EDTA/PBS for $5 \mathrm{~min}$ at RT and then maintained overnight under $5 \% \mathrm{CO}_{2}$ at $37^{\circ} \mathrm{C}$ in complete medium. All cell cultures were then washed and reincubated until the time of further analysis.

\section{Leishmania Culturing}

L. major (strain MHOM/RI/-/WR-173) and L. amazonensis (strain $\mathrm{MHOM} / \mathrm{Br} 88 / \mathrm{Ba}-125)$ parasites were isolated from the lymph nodes of infected C57BL/6 mice. Axenic cultures of L. amazonensis or L. major promastigotes were maintained in culturing for up to six successive passages in Schneider's
Insect Medium (Sigma, St. Louis, MO, United States) supplemented with $50 \mu \mathrm{g} / \mathrm{mL}$ gentamicin (Gibco, Grand Island, NY, United States) and 10\% fetal bovine serum (Gibco, Grand Island, NY, United States), following a slightly modified previously described protocol (2). Axenic promastigotes were cultivated in an incubator at $24^{\circ} \mathrm{C}$ and monitored daily.

\section{Kinetics of BMMØ Infection With}

\section{L. amazonensis or L. major Promastigotes}

$\mathrm{CBA}$ mouse BMM $\varnothing$ were harvested and distributed at $5 \times$ $10^{6}$ cells per well on 24 -well plates, and then infected with stationary-phase L. amazonensis or L. major promastigotes at a parasite to macrophage ratio of 10:1. After $1.5,3$, or $6 \mathrm{~h}$, cells were washed and fixed in $4 \%$ paraformaldehyde for $15 \mathrm{~min}$. A separate group of cells were then washed to remove noninternalized parasites (after $6 \mathrm{~h}$ of infection) and these cells were reincubated for an additional 12 or $24 \mathrm{~h}$ at $37^{\circ} \mathrm{C}$ and then fixed. All cells were then subsequently mounted on coverslips using a ProLong Gold Antifade kit with DAPI (Life Technologies). The percentage of infected cells and the number of parasites per infected macrophage were determined by counting no $<400$ cells in random fields under an Olympus BX 51 fluorescence microscope using an 100x/1.4 objective in accordance with a protocol previously described by Huynh et al. (32).

\section{Preparation of Protein Extracts of BMMØ Infected With L. amazonensis or L. major Promastigotes and Processing for Tandem Liquid Chromatography-Mass Spectrometry}

CBA mouse BMM $\varnothing$ were cultivated harvested and cultivated in DMEM complete medium (DMEM medium supplemented with $10 \%$ inactivated FCS, $2 \mathrm{~g} / \mathrm{L}$ of sodium bicarbonate, $25 \mathrm{mM}$ HEPES, $1 \mathrm{mM}$ of glutamine, and $0.2 \%$ of ciprofloxacin) at $37^{\circ} \mathrm{C}$ in $5 \% \mathrm{CO}_{2}$ for $18-24 \mathrm{~h}$ before infection at $5 \times 10^{6}$ cells per well on six-well plates. Uninfected $\mathrm{M} \varnothing$ were used as controls. In parallel, CBA $\mathrm{M} \varnothing$ were infected with L. major or L. amazonensis stationary-phase promastigotes, at a parasite to macrophage ratio of 10:1. After a $6 \mathrm{~h}$ infection period, the control and infected cells were washed, and part of the cells was reincubated for an additional $24 \mathrm{~h}$ at $37^{\circ} \mathrm{C}$. Finally, proteins were extracted from uninfected and infected $M \varnothing$. Each experimental group was cultured in duplicate, and each biological experiment was repeated at least five times. All cell groups were, then, harvested and protein extraction was performed in $150 \mu \mathrm{L}$ of lysis buffer $(7 \mathrm{M}$ urea, $2 \mathrm{M}$ thiourea, $40 \mathrm{mM}$ Tris, and $4 \%$ CHAPS), supplemented with a Protease Inhibitor Cocktail Tablets, Complete, Mini, EDTA-free Protease Inhibitor cocktail (Roche, IN, USA). The solutions were homogenized for $30 \mathrm{~min}$ and centrifuged at $13,800 \times \mathrm{g}$ for $20 \mathrm{~min}$. After determining protein concentrations using a Bio-Rad Protein Assay Kit (Bio-Rad Laboratories Inc., Hercules, CA, USA), the contaminants were removed using a 2D clean-up kit (GE Healthcare, Waukesha, WI, USA). Following purification, the samples were resuspended in a solution of $8 \mathrm{M}$ urea and $5 \mathrm{mM}$ dithiothreitol (DTT) and incubated for 1-2h. Subsequently, 
a solution containing $200 \mathrm{mM}$ iodoacetamide (IAA) in $1 \mathrm{M}$ ammonium bicarbonate $\left(\mathrm{NH}_{4} \mathrm{HCO}_{3}\right)$ was mixed into the sample solution and incubated for $45 \mathrm{~min}$ at room temperature under total darkness. Next, the samples were incubated with $200 \mathrm{mM}$ of DTT for $20 \mathrm{~min}$ at room temperature. All samples were then diluted in $50 \mathrm{mM}$ of $\mathrm{NH}_{4} \mathrm{HCO}_{3}$ and $2 \mathrm{mM}$ of $\mathrm{CaCl}_{2}$, followed by the addition of a trypsin solution for protein digestion and the generation of tryptic peptides at a ratio of 1:30 (trypsin: protein). Digestion occurred over $16-18 \mathrm{~h}$ at $37^{\circ} \mathrm{C}$ and was interrupted by the addition of a $10 \%$ trifluoroacetic acid solution and the subsequent $\mathrm{pH}$ adjustment to 5.0. The resulting tryptic peptides were desalted on C8 cartridges (Michrom BioResources, Auburn, CA, USA) and subjected to 2D Nano tandem liquid chromatography-mass spectrometry (LC-MS/MS) analysis using a Dionex nano-LC system (Dionex Corporation, Sunnyvale, CA, USA). To perform first-dimension separation, a $300 \mu \mathrm{m}$ ID SCX column (PolyLC Polysulfoethyl A, $150 \times 0.3 \mathrm{~mm}, 5 \mu \mathrm{m}$, $200 \mathrm{~A})$ was used with a 15 -step gradient $(0-100 \%, \mathrm{pH} 3.6-6.5)$ of ammonium formate (generated in-house, $0.8 \mathrm{M}$ solution), with each step lasting $1 \mathrm{~h}$, at a flow rate of $5 \mu \mathrm{L} / \mathrm{min}$. The peptides eluted from the SCX column were trapped on a C4 precolumn (Dionex PepMap300, $5 \mu \mathrm{m}, 300 \mathrm{~A}, 300 \mu \mathrm{m}$ ID $\times$ $5 \mathrm{~mm}$ ), desalted [0.1\% formic acid, $2 \%$ acetonitrile (ACN)] and separated on a $75 \mu \mathrm{m}$ ID C18 column (Dionex NAN75-15-1503-C18 PepMap100 stationary phase, $3 \mu \mathrm{m}$ ) using an acetonitrile gradient at a flow rate of $200 \mathrm{~nL} / \mathrm{min}$. Finally, the eluted peptides were electrosprayed, using a potential of $1.8-2.2 \mathrm{kV}$, onto an LCQ Deca XP(Plus) ion trap mass spectrometer (Thermo Finnigan Corporation, San Jose, CA, USA) in data-dependent mode. A full-scan MS spectra survey was acquired at $\mathrm{m} / \mathrm{z}$ from 350 to 2,000 , after which the four most abundant ions were selected and fragmented for the production of tandem mass spectra. Any target ions previously selected twice for MS/MS were dynamically excluded for $3 \mathrm{~min}$. Peptide dissociation was performed at $35 \%$ of the normalized collision energy, and the MS/MS spectra were recorded in profile mode.

\section{Protein Identification}

In order to differentiate between macrophage and Leishmania proteins, the MS/MS spectra were searched against both the Mus musculus and L. amazonensis local protein databases using the SEQUEST algorithm in Bioworks v3.2 software. The $\mathrm{X}_{\text {corr }}$ and $\triangle \mathrm{Cn}$ threshold values for a $1 \%$ false discovery rate (FDR) were used to obtain the peptide ID list. The FDR was calculated using a reverse database and the modification parameters were set to +57.02146 for cysteine alkylation and +15.99492 for methionine oxidation. The spectra search allowed for a maximum mass deviation of $3 \mathrm{amu}$ and two missed cleavage sites. The only peptides selected for further analysis were those identified as possessing fully tryptic termini with cross-correlation scores $>1.9$ for single-charged, 2.3 for double-charged, and 3.75 for triplecharged, with a delta-correlation score over 0.1 and a probability score lower than $1 \times 10^{-5}$. All peptides that met these criteria were included in the differential expression analysis, in which a quantitative metric was applied. For data normalization, the counts corresponding to each peptide were divided by the total sum of all the peptide counts in a given sample, and then divided by the highest total sum of all the peptide counts among all samples assessed throughout the entire experiment. These results were then transformed to $\log 2$ and two-way ANOVA analysis was applied, in which Log2 fold change ( $\left.\log _{2} \mathrm{FC}\right)$ and FDR ( $q$-value) were assessed.

\section{Datamining Analysis}

Using Weka software, the CfsSubsetEval and BestFirst features were used to select attributes in the dataset strongly associated with experiment conditions (Weka 3.9.3, University of Waikato). Principal Component Analysis (PCA) was employed to reduce dimensionality of selected attributes in the dataset strongly associated with experiment conditions (Weka 3.9.3, University of Waikato). Using Orange software, the Find Informative Projections feature was used to identify well-separated patterns/clusters within the dataset based on the new attributes generated by PCA (Orange 3.17.0, University of Ljubljana). IPA software was used for enrichment analysis to identify relevant biological pathways (QIAGEN Inc., https://www.qiagenbioinformatics.com/products/ingenuitypathway-analysis).

\section{Expression of NRF2, p62, HO-1, and Ferritin in BMMØ Infected With $L$. amazonensis, L. major Promastigotes or Stimulated With LPG}

For these experiments, Western blotting was used to calculate the ratios between the amounts of NRF2, p62, HO-1, ferritin, and actin in the extracts of CBA BMM $\varnothing$. MØ were infected with L. amazonensis or L. major, or stimulated with purified intact LPG extract at $10 \mu \mathrm{g} / \mathrm{mL}$ from each of these Leishmania species (for HO-1 experiments) for $6 \mathrm{~h}$, and a separate group of cells were then washed to remove non-internalized parasites and reincubated for an additional 24 or $48 \mathrm{~h}$. LPG extraction and purification was performed in accordance with a protocol previously described by Nogueira et al. (33). Cobalt protophorphyrin IX (CoPP), a pharmacologic inductor of $\mathrm{HO}$ 1 , was used as positive control of HO-1 expression. For total protein extraction (p62, HO-1, ferritin and actin), BMM $\varnothing(2 \times$ $10^{6}$ cells) were washed twice with ice-cold PBS and then lysed in $100 \mu \mathrm{l}$ of lysis buffer (50 mM Tris- $\mathrm{HCl}, \mathrm{pH} 7.5,5 \mathrm{mM}$ EDTA, $10 \mathrm{mM}$ EGTA, $50 \mathrm{mM} \mathrm{NaF}, 20 \mathrm{mM} \beta$-glycerophosphate, $250 \mathrm{mM}$ $\mathrm{NaCl}, 0.1 \%$ Triton $\mathrm{X}-100,1 \mu \mathrm{g} / \mathrm{ml} \mathrm{BSA}$, and a 1:100 dilution of protease inhibitor cocktail, Sigma, St. Louis, MO, USA). For nuclear protein extraction (NRF2), cells were washed twice with $1 \mathrm{x}$ PBS and then lysed with $100 \mu \mathrm{L}$ of buffer A (HEPES $10 \mathrm{mM}$ $\mathrm{pH}$ 7.9. $10 \mathrm{mM} \mathrm{KCl}, 0.1 \mathrm{mM}$ EDTA, $0.1 \mathrm{mM}$ EGTA, NP-40 0, $25 \%(\mathrm{v} / \mathrm{v})$; cocktail of protease inhibitors) for $10 \mathrm{~min}$ on ice. All lysed cells were then centrifuged at $14,000 \mathrm{~g}$ for $1 \mathrm{~min}$ at $4^{\circ} \mathrm{C}$, and the pellet was resuspended in $60 \mu \mathrm{L}$ of buffer $\mathrm{C}(20 \mathrm{mM}$ HEPES pH 7.9, 0.4 M NaCl, 1 mM EDTA, 1 mM EGTA, 20\% glycerol, protease inhibitor cocktail) and incubated on ice for $20 \mathrm{~min}$. The lysate was centrifuged at $14,000 \mathrm{~g}$ for $5 \mathrm{~min}$, and the supernatant containing nuclear proteins was collected in a new tube. Protein extract was subjected to electrophoresis on $10 \%$ SDS-polyacrylamide gel and transferred to nitrocellulose 
membranes (Amersham Biosciences, Piscataway, NJ, USA). After blocking with $5 \%$ non-fat dry milk in TBS with $0.1 \%$ Tween20 (TBS-T), blots were incubated overnight with antibodies against NRF2, p62, HO-1, ferritin, and $\beta$-actin, followed by secondary antibody labeling. All membranes were then washed thrice with $0.1 \%$ TBS-T and blots were developed with an ECL Chemiluminescence Kit (Thermo Fisher Scientific, Rockford, IL, United States). Bands were detected using a Luminescent Image Analyzer and Image Quant Las 4000 software. Densitometry quantification was performed using Image J software. In addition, HO-1 validation was also performed by ELISA in accordance with a protocol previously described (19).

\section{Quantification of Nitric Oxide (NO) Production}

To assess the differential production of NO by L. amazonensisor L. major- infected BMMØ, cells were primed with $50 \mathrm{UI} / \mathrm{mL}$ IFN- $\gamma$ (R\&D Systems, Minneapolis, MN, USA) for $24 \mathrm{~h}$ and subsequently infected. After $6 \mathrm{~h}$ part of the cells was fixed and part was washed and reincubated in DMEM medium containing IFN- $\gamma$ for an additional $24 \mathrm{~h}$. Infected cells incubated in IFN- $\gamma-$ free medium were used as a negative control. NO production was measured in culture supernatants by determining nitrite accumulation using the Griess reaction.

\section{Binding and Internalization of HoloTf by Infected BMMØ}

For holoTf uptake assays, BMM $\varnothing$ were plated on 24-well plates at a concentration of $2 \times 10^{5}$ per well, infected with L. amazonensis or L. major (10:1) or left uninfected. After $6 \mathrm{~h}$ part of the cells was fixed and part was washed and then reincubated with $300 \mathrm{nM}$ of holoTf-Texas Red (Molecular Probes) at $4{ }^{\circ} \mathrm{C}$ for $30 \mathrm{~min}$ in complete DMEM medium, in which FCS was replaced with $1 \%$ de Nutridoma-SP (Roche). Cells were then washed with cold saline and reincubated in holoTf-free medium for an additional $40 \mathrm{~min}$ at $37^{\circ} \mathrm{C}$. Finally, cells were washed again with cold saline and either fixed with $4 \%$ paraformaldehyde for $15 \mathrm{~min}$ or reincubated for an additional $24 \mathrm{~h}$ before fixation. Coverslips were mounted using a ProLong Gold Antifade kit containing DAPI (Life Technologies). Images were acquired on a Leica SP8 confocal microscope and processed using ImageJ software. Fluorescence intensity from 30 cells from each group after binding or internalization of holoTf was quantified in whole cell and parasitophorous vacuoles of each infected macrophage using ImageJ software. Statistical differences were evaluated using the Student's $t$-test $\left({ }^{*} p<0.05\right)$. Data are representative of three independent experiments.

\section{Statistical Analysis}

All statistical analysis was carried out using GraphPad Prism Software (version Mac 5.0c). After evaluating the normality of data, the unpaired Student's $t$-test or the Mann-Whitney test were used for comparisons between two groups, for Gaussian and nonGaussian distributions. For comparisons among three or more groups, one-way ANOVA was used for Gaussian distribution,
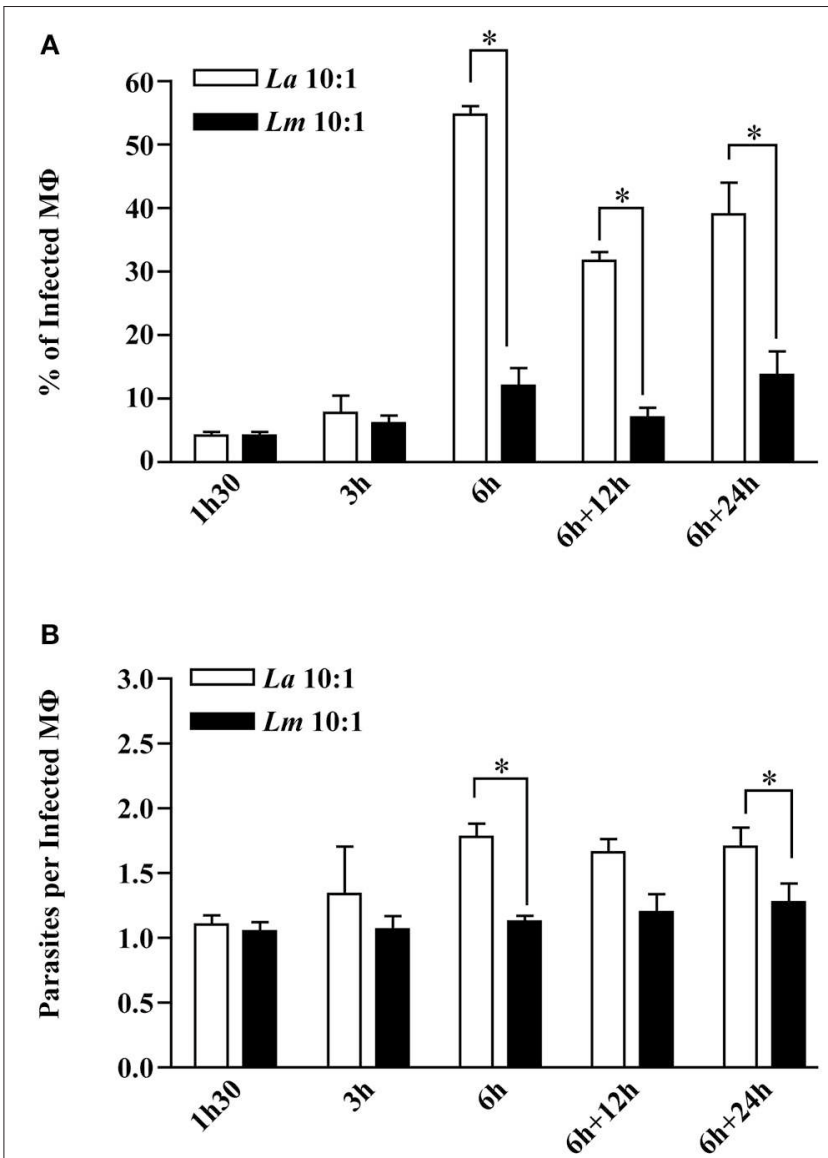

FIGURE 1 | Kinetics of CBA BMM $\varnothing$ infection by L. amazonensis or L. major. $\mathrm{BMM} \varnothing$ were infected as described under Materials and Methods. Cells were fixed and then DAPI-stained after 1.5, 3, or $6 \mathrm{~h}$. Additionally, other cells infected for $6 \mathrm{~h}$ were washed and re-incubated for an additional 12 or $24 \mathrm{~h}$. (A) Percentage of infected BMM $\varnothing$ and (B) amastigotes per macrophage were quantified by fluorescent microscopy. Statistical differences were evaluated using the Mann-Whitney test $\left({ }^{*} p<0.05\right)$. Data represent means \pm SE of three independent experiments.

while for non-Gaussian distribution, the Kruskal-Wallis nonparametric test was employed. Differences among tested groups were considered statistically significant when $p<0.05$.

\section{RESULTS}

\section{Kinetic Model of BMMØ Infection With} L. amazonensis or L. major Promastigotes Kinetic analysis of BMM $\varnothing$ infection involving L. amazonensis or L. major promastigotes revealed that the percentage of infected $\mathrm{M} \varnothing$ and the number of parasites per infected cell were similar in both infected cell groups at 1.5 and $3 \mathrm{~h}$ after parasites were added to cell cultures (Mann-Whitney, $p<0.05$, Figures 1A,B). At $6 \mathrm{~h}$ of infection, the percentages of infected BMM $\varnothing$ for $L$. amazonensis and L. major infection were different, respectively, 54.88 and $12.00 \%$. After reincubation times, the percentage L. amazonensis- and L. major-infected $\mathrm{M} \varnothing$ maintained these 


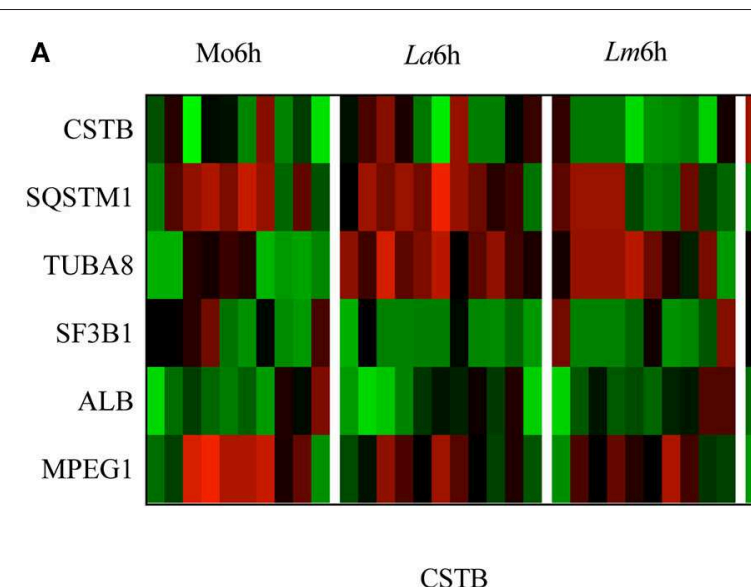

B

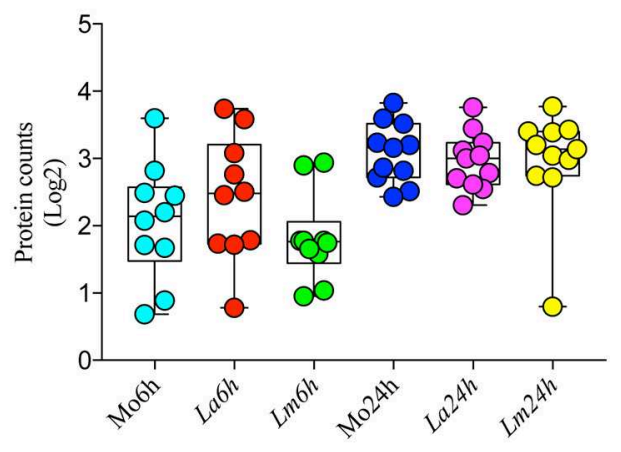

D

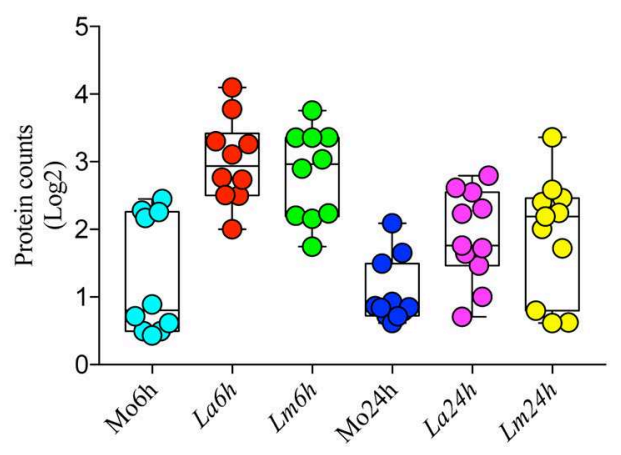

F

ALB

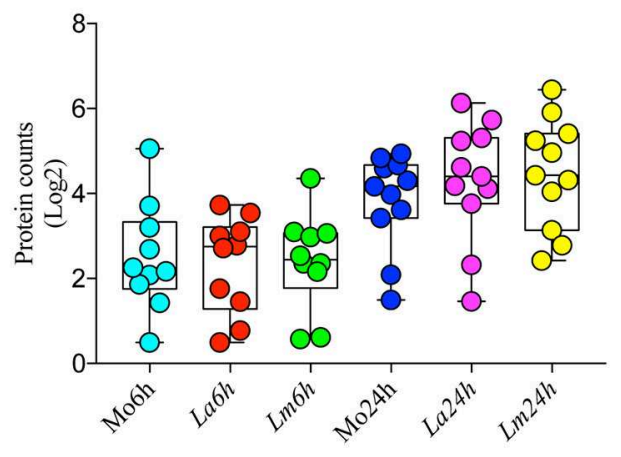

C
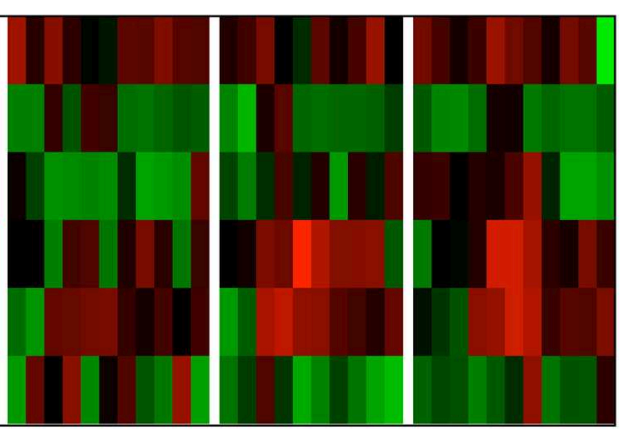

SQSTM1

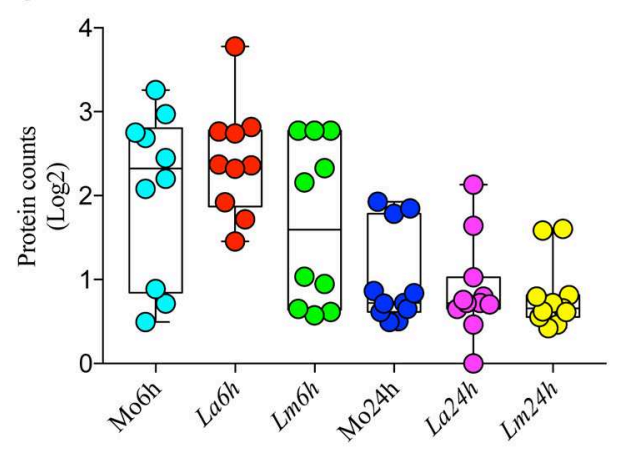

E

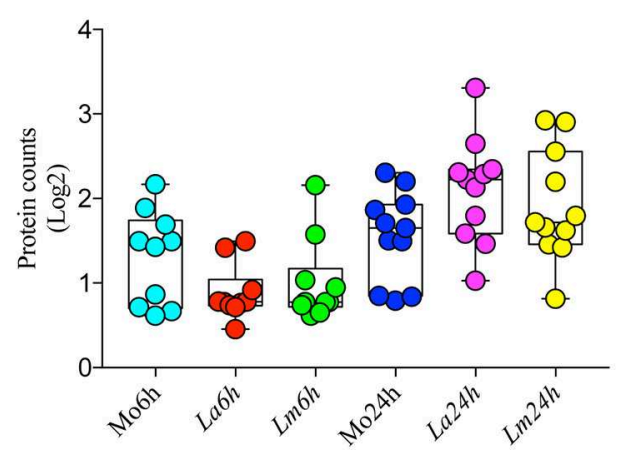

$\mathbf{G}$

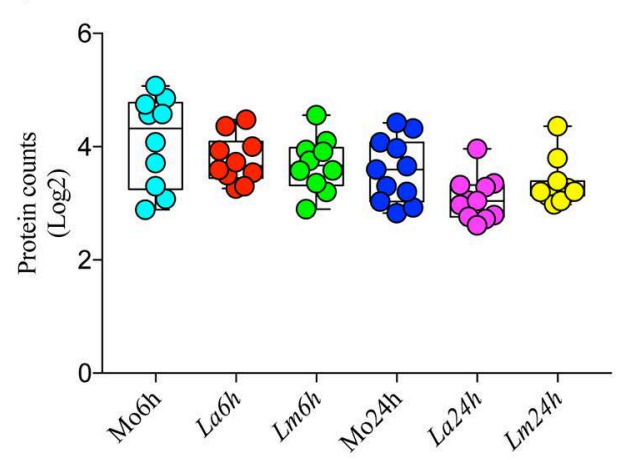

FIGURE 2 | Selected proteins strongly associated with experimental conditions. (A) Heatmap showing representative Z-scores based on selected protein counts corresponding to each experimental condition replicate. (B-G) Quantitative values of log2 protein counts from each experimental condition represented by box plots and dot plots. 


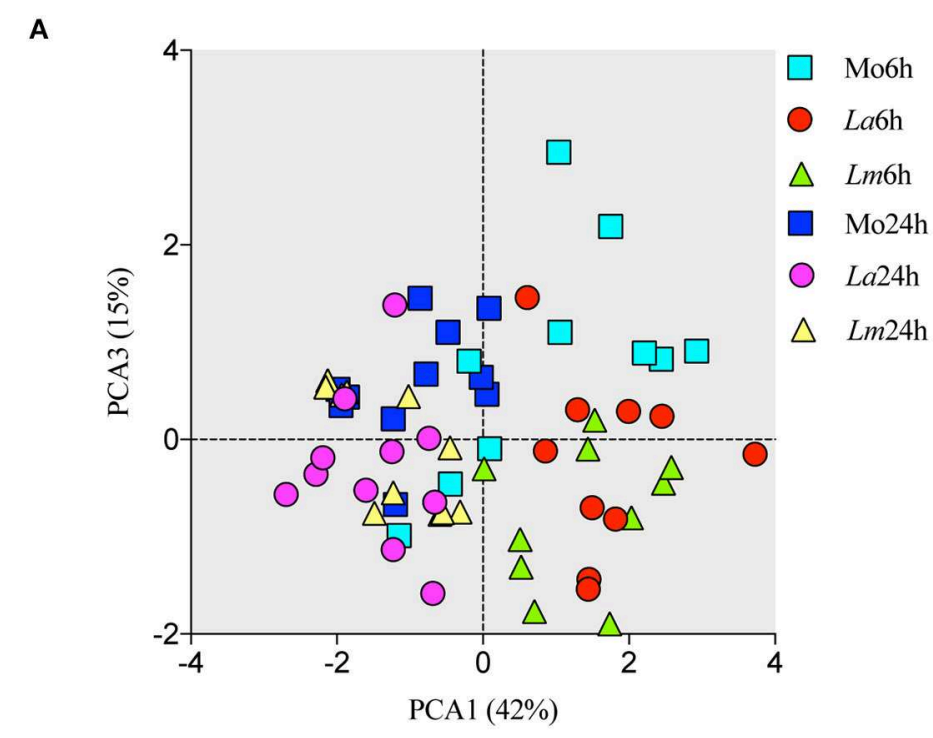

B

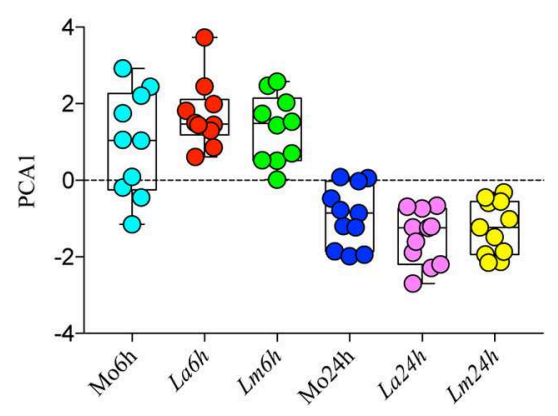

E

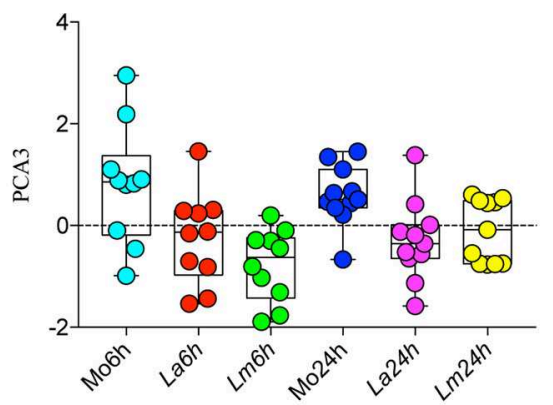

C

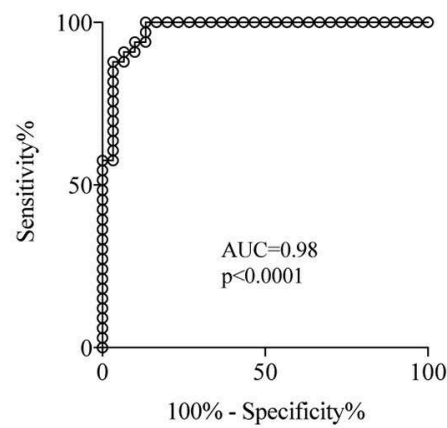

F

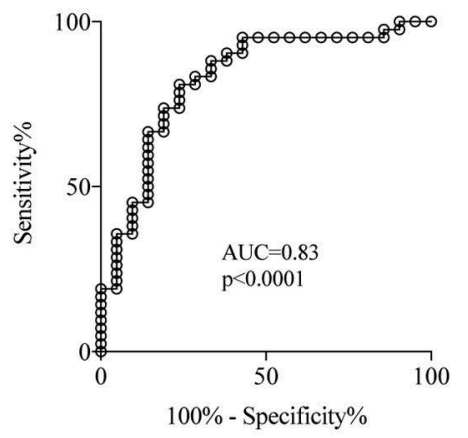

D

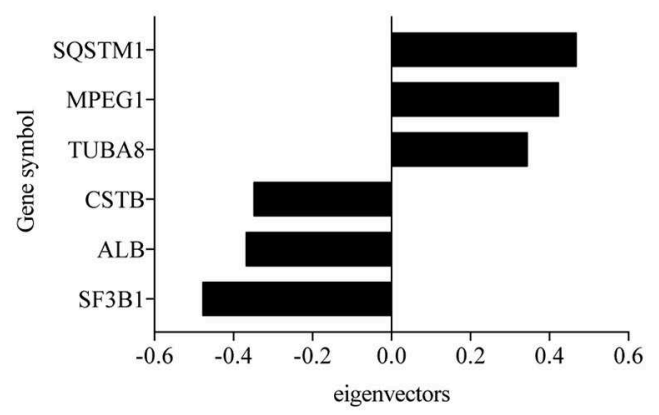

G

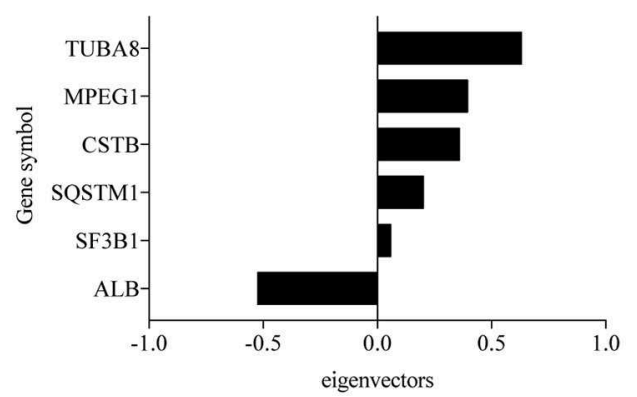

FIGURE 3 | Principal Component Analysis (PCA) associated with experimental conditions. PCA was employed to reduce dimensionality and extract principal components using linear combinations of the six selected proteins in the dataset (A) Principal component 1 (PCA1) and principal component 3 (PCA3) scores are depicted in a two-dimensional scatterplot for each sample. Associations between cell culturing times and PCA1 scores (B,C) and Leishmania infection conditions and PCA3 scores (E,F) are represented by box plot and dot plot graphs $\mathbf{( B , E )}$ and ROC curve analysis (C,F). (D, G) Bar graph depicting protein eigenvectors values for PCA1 (D) and PCA3 (G). PCA1 scores are characterized by the positive eigenvector values of SQSTM1, MPEG1, and TUBA8, and the negative eigenvector values of CSTB, ALB, and SF3B1. PCA3 scores are characterized by the positive eigenvector values of TUBA8, MPEG1, and CSTB, and the negative eigenvector values of SQSTM1, SF3B1, and ALB. 
A

Production of Nitric Oxide and Reactive Oxygen Species in Macrophages Actin Cytoskeleton Signaling

ILK Signaling

Leukocyte Extravasation Signaling Signaling by Rho Family GTPases Paxillin Signaling Integrin Signaling Fc $\gamma$ Receptor-mediated Phagocytosis in Macrophages and Monocytes RhoGDI Signaling RhoA Signaling VEGF Signaling IL-8 Signaling Regulation of Actin-based Motility by Rho Sirtuin Signaling Pathway Gaq Signaling NRF2-mediated Oxidative Stress Response Rac Signaling PI3K/AKT Signaling EIF2 Signaling mTOR Signaling Sumoylation Pathway Role of NFAT in Regulation of the Immune Response Phospholipase C Signaling Pancreatic Adenocarcinoma Signaling Aryl Hydrocarbon Receptor Signaling

B

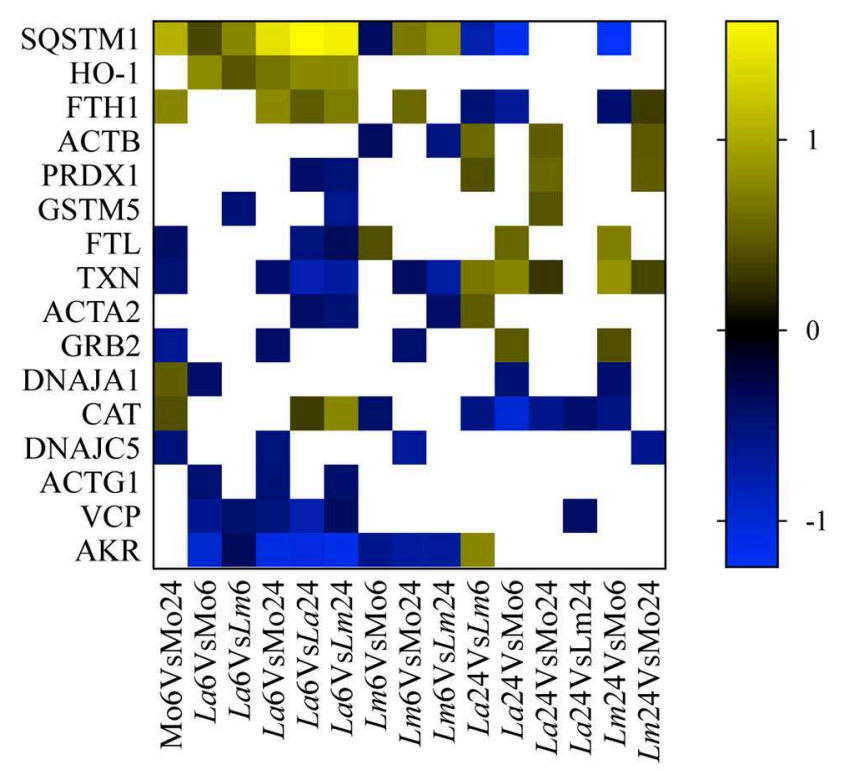

FIGURE 4 | Canonical pathway enrichment analysis. (A) Heatmap representing enriched canonical pathways produced by IPA from 15 datasets generated from an all-vs.-all comparison of the study conditions: $Z$ score $=-1$ to 1 and $\mid-\log 10(p$-value $) \mid>1$.3. Blue blocks and yellow blocks represent inhibited and activated

(Continued) 
FIGURE 4 | canonical pathways, respectively. White blocks represent canonical pathways without significance in a given experimental comparison. (B) Heatmap representing Log2 fold changes of significantly regulated genes (multiple comparison two-way ANOVA, $q<0.05$ and $|\log 2 \mathrm{FC}|>0.2$ ) present in the dataset included in the NRF2-Mediated Oxidative Stress canonical pathway. Blue blocks and yellow blocks represent down-regulated and up-regulated genes, respectively. White blocks are representative of genes not significantly regulated in a given experimental comparison.

differences, respectively, 31.69 vs. $7.00 \%$ at $12 \mathrm{~h}$, and 38.94 and $13.69 \%$ at $24 \mathrm{~h}$ (Mann-Whitney, $p<0.05$, Figure 1A). Similarly, the average number of parasites per L. amazonensis- or L. majorinfected macrophage were distinct, respectively: 1.78 vs. 1.13 at $6 \mathrm{~h} ; 1.70$ vs. 1.27 at $24 \mathrm{~h}$ (Mann-Whitney, $p<0.05$, Figure $1 \mathrm{~B}$ ).

\section{LC-MS/MS Analysis and Datamining Identified Differentially Expressed Proteins Associated With Leishmania Infection in Murine MØ}

To investigate the differences in BMM $\varnothing$ susceptibility between L. amazonensis and L. major infection, a proteomic approach was employed to obtain global protein cell signatures at an initial time point $(6 \mathrm{~h})$ and at a later time point $(24 \mathrm{~h})$ following parasite washout. BMM $\varnothing$ protein identification and characterization from ten independent experiments were performed using LCMS/MS with a MudPIT approach. The SEQUEST algorithm revealed a total of 2,838 significantly expressed proteins. Subsequently, data pre-processing was performed to normalize the samples before determining the protein signatures for CBA BMM $\varnothing$ infected with each Leishmania species. Using a supervised learning method (CfsSubsetEval and BestFirst) for filtering proteins, six proteins [cystatin B (CSTB), sequestosome 1 (SQSTM1 or p62), tubulin alpha 8 (TUBA8), splicing factor $3 b$ subunit 1 (SF3B1), albumin (ALB), and macrophage expressed 1 (MPEG1)] were identified as strongly associated with experimental conditions (Figure 2). To evaluate the global significance of these proteins in the context of Leishmania infection, an unsupervised method (Principal Component Analysis) reduced the dimensionality of the selected proteins and generated new attributes, including PCA1 and PCA3. Using the Find Informative Projection option, PCA1 (42\%) and PCA3 (15\%) combined were able to account for $57 \%$ of the variance of the entire dataset (Figure 3A). Of note, using the eigenvector values associated with PCA1 and PCA3, we were able to confidently classify the following conditions with each feature: PCA1, cell culturing times $(6 \times 24 \mathrm{~h})$ (ROC curve analysis, $\mathrm{AUC}=0.98, p<0.0001$ ) (Figures 3B-D); PCA3, Leishmania infection conditions (uninfected $\mathrm{M} \varnothing \times$ L. amazonensis- or L. major-infected MØ) (ROC curve analysis, $\mathrm{AUC}=0.83$, $p<0.0001$ ) (Figures 3E-G).

\section{Biological Enrichment Analyses in Differentially Expressed Proteins Associated With Leishmania Infection in Murine Mø Reveal a NRF2-dependent Mechanism}

To perform a biological interpretation of the six identified proteins IPA was used for enrichment analysis to identify CPs and UTFs filtered by Transcription regulators in three steps. Firstly, biological enrichment analysis using IPA identified 21 CPs and 142 possible UTFs containing at least one of the six genes (data not shown). Next, IPA was performed in 15 datasets generated from an all-vs.-all comparisons of the study conditions (total of 365 statistically significant mapped proteins, multiple comparison two-way ANOVA, $q<0.05$ and $\left|\log _{2} \mathrm{FC}\right|$ $>0.2$, Supplementary Table 1 ) and identified 25 CPs and 51 possible UTFs using a $\mathrm{Z}$ score $=-1$ to 1 and $\mid-\log 10(p$ value) $\mid>1.3$ (Figures 4A, 5A). Finally, to filter the possibilities for validation, we overlaid the biological enrichment analysis results from the six proteins with the 15 datasets generated, which revealed that only 4 CPs (Production of Nitric Oxide and Reactive Oxygen Species in MØ, IL-8 Signaling, Sirtuin Signaling Pathway, and NRF2-mediated Oxidative Stress Response) and 7 UTFs [MYC proto-oncogene (MYC), transcription factor 7 like 2 (TCF7L2), promyelocytic leukemia (PML), CCAAT enhancer binding protein alpha (CEBPA), NFE2L2 (NRF2), tumor protein p53 (TP53) and signal transducer, and activator of transcription 6 (STAT6)] were strongly involved in the infection process. Among these findings, the NFE2L2 signature was the only molecule both present in both CPs and UTFs. The NRF2 CP and the NRF2 UTF analyses identified a group of molecules besides SQSMT1 (Figures 4B, 5B). The involvement of the iron metabolism pathway was demonstrated by the presence of HO-1 and ferritin, probably, recruited by NRF2. Of note, HO-1 was strongly associated only with $L$. amazonensis infection at $6 \mathrm{~h}$ (data not shown), while ferritin was regulated among both parasites (data not shown). These differently expressed proteins were then validated by ELISA or Western-blotting at time points varying from 6 to $48 \mathrm{~h}$ post-infection.

\section{NRF2 Expression by L. amazonensis- or L. major-Infected BMMØ}

Recently, it was demonstrated that $L$. amazonensis and $L$. braziliensis induce NRF2 expression via the activation of the protein kinase $\mathrm{R}$ (PKR) pathway. Importantly, NRF2 activation resulted in infection tolerance in vivo, which enhanced intracellular pathogen survival (22). Accordingly, here we sought to investigate whether NRF2 would be differentially expressed by L. amazonensis and L. major-infected cells. Using Westernblotting, we detected elevated levels of NRF2 transcription factor translocated to the nuclei (Figures 6A,B) and p62 protein (Figures 6C,D) at $6 \mathrm{~h}$ in both L. amazonensis- and L. major-infected cells in comparison to uninfected control BMMØ, although to a greater extent in L. amazonensisinfected BMM $\varnothing$, which is the strain highly virulent to CBA mouse MØ (Figure 6). 
A

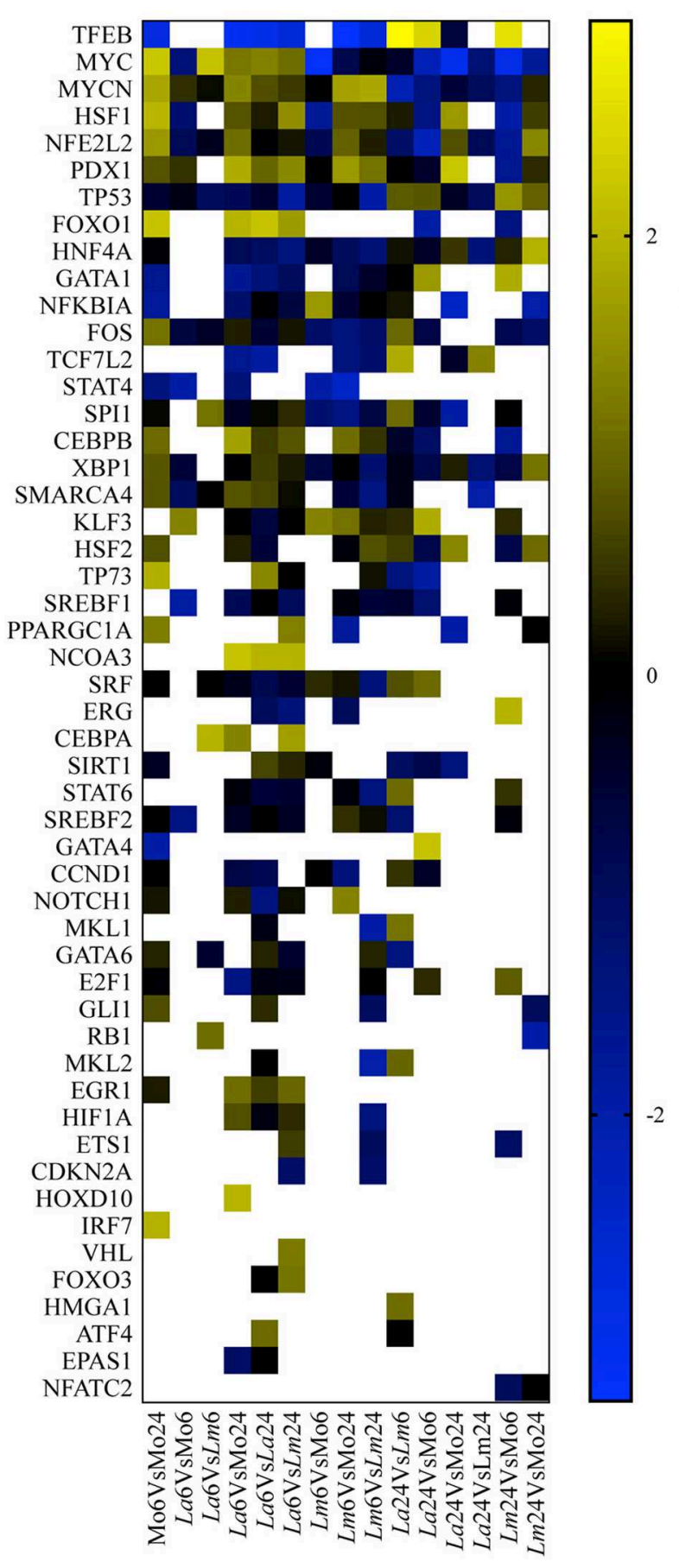

B

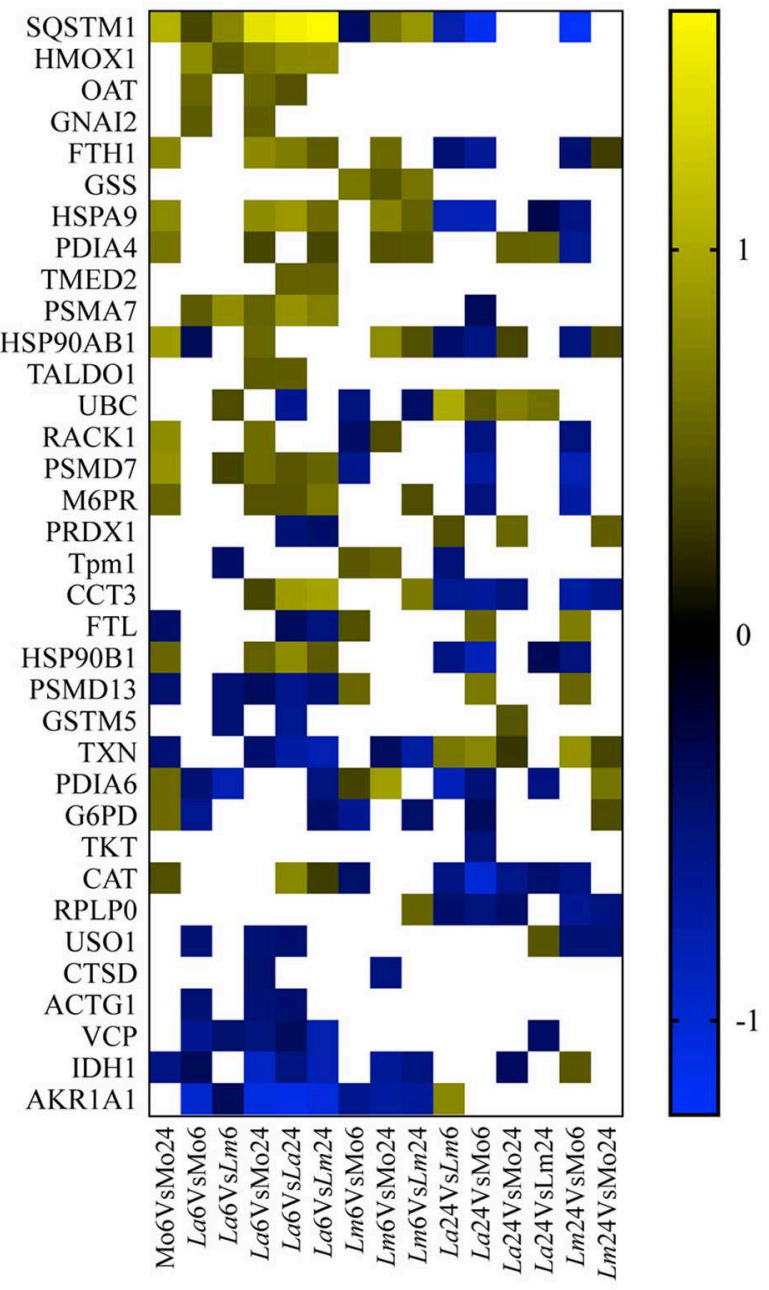

FIGURE 5 | UTF enrichment analysis. (A) Heatmap representing enriched UTFs, filtered by transcription regulators with Z scores $=-1$ to 1 and $\mid-$ Log10(p-value)| > 1.3, obtained by IPA using 15 datasets generated from an all-vs.-all comparison of the study conditions. Blue blocks and yellow blocks represent inhibited and activated UTFs, respectively. White blocks represent UTFs without significance in a given experimental comparison. (B) Heatmap representing Log2 fold changes in significantly regulated genes (multiple comparison two-way ANOVA, $q<0.05$ and $\mid$ Log $2 \mathrm{FC} \mid>0.2$ ) present in the dataset of the NRF2/NFE2 L2 UTF pathway. Blue blocks and yellow blocks represent down-regulated and up-regulated genes, respectively. White blocks are representative of genes not significantly regulated in a given experimental comparison. 


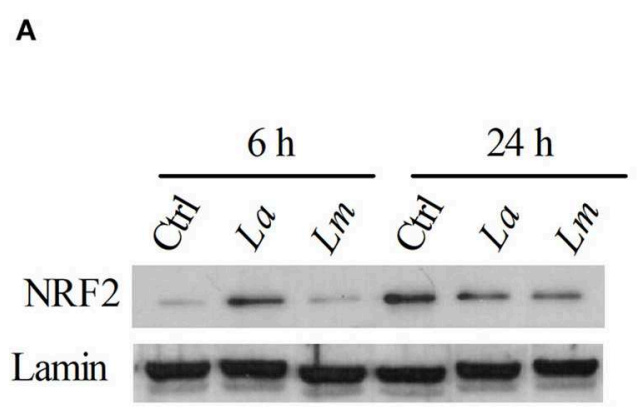

C

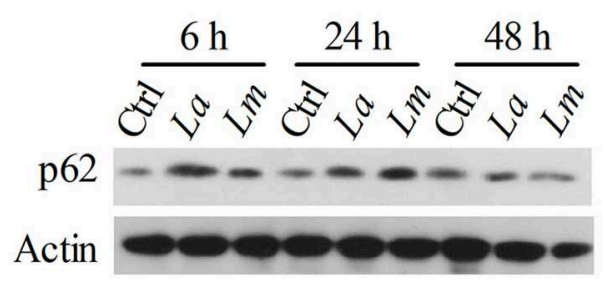

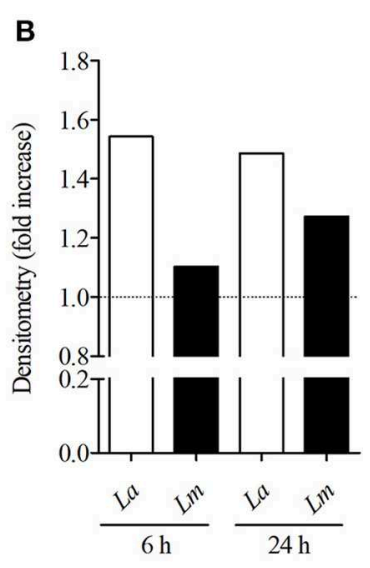

D

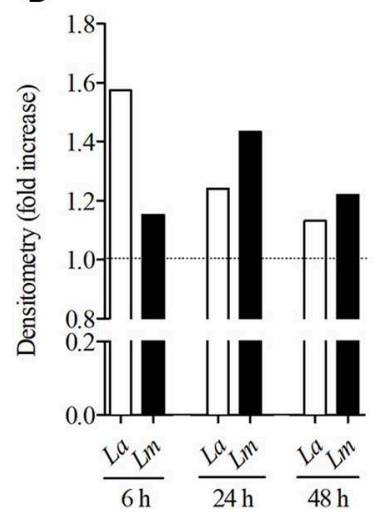

FIGURE 6 | L. amazonensis infection induces higher levels of NRF2 and p62 in CBA BMMØ. NRF2 and p62 protein levels were evaluated following L. amazonensis and $L$. major infection. BMM $\varnothing$ were infected or not with $L$. amazonensis or $L$. major as described in Materials and Methods. After 6,24 , or $48 \mathrm{~h}$ of infection, M $\varnothing$ were washed to remove extracellular parasites and protein levels were quantified by Western blotting. (A) Effect of $L$. amazonensis or $L$. major infection on NRF2 protein levels. Anti-laminin antibodies were used as loading controls. (B) NRF2/laminin fold increase ratios in comparison to control levels (dashed line), as determined by densitometry. Results shown in (A,B) are representative of two independent experiments. (C) Effect of $L$. amazonensis or $L$. major infection on p62 protein levels. Anti-actin antibodies were used as loading controls. (D) p62/actin fold increase ratios in comparison to control levels (dashed line), as determined by densitometry. Results shown in (C,D) are representative of three independent experiments.

\section{Validation of Proteins Differentially Expressed by L. amazonensis- and}

\section{L. major-Infected BMMØ}

Western-blotting analysis confirmed that NFR2 activated different signaling pathways in BMMØ infected with each strain of Leishmania. IPA analysis indicated that NRF2 is an upstream regulator known to be involved in the activation of several proteins identified by SEQUEST analysis, of which HO-1 was validated herein. Accordingly, the protein involved in antioxidant response, HO-1, was found to be highly expressed at $6 \mathrm{~h}$ by L. amazonensis-infected BMMØ (Figures 7A,B), while increased levels of the main iron storage protein, ferritin, was detected at $48 \mathrm{~h}$ in L. major-infected MØ (Figures 7C,D). The Western-blotting assay showed higher expression of HO-1 in L. amazonensis-infected MØ, which was confirmed by an ELISA that specifically detected higher amounts of HO- 1 in cell extracts at $24 \mathrm{~h}$ after infection (Figure 7G). Also, BMMØ incubated with LPG isolated from L. amazonensis expressed higher levels of $\mathrm{HO}-1$, when compared to those incubated with LPG isolated from L. major parasites (Figures 7E,F).

\section{Nitric Oxide (NO) Production by BMM $\varnothing$ Infected With $L$. amazonensis or $L$. major Promastigotes}

Since there is clear evidence linking the nitric oxide production by infected cells, HO-1 expression and the capability of host cells to control Leishmania infection in vivo, as well as in vitro (19), we decided to investigate whether the control of $L$. major induced by CBA BMM $\varnothing$ would be associated with the production of microbicidal molecules to a greater extent than in L. amazonensis-infected BMMØ. All control cells, whether uninfected, infected but not stimulated, or simply stimulated with IFN- $\gamma(100 \mathrm{UI} / \mathrm{mL})$ produced low levels of NO, without any significant differences. Only infected cells stimulated with IFN- $\gamma$ produced increased amounts of $\mathrm{NO}$, and 1.5 times more $\mathrm{NO}$ was detected in L. major-infected ВMMØ than in L. amazonensisinfected cells at $24 \mathrm{~h}$ after infection (Figure $7 \mathbf{H}$ ). 
A

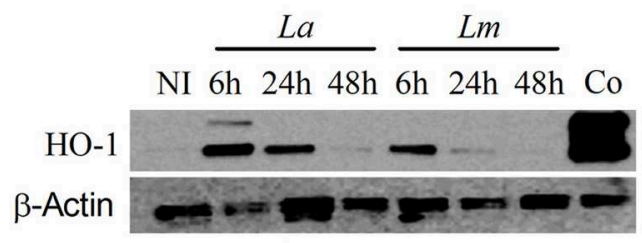

C

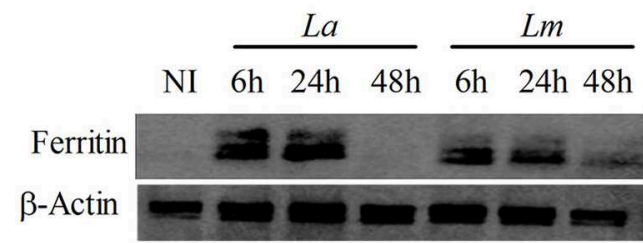

E

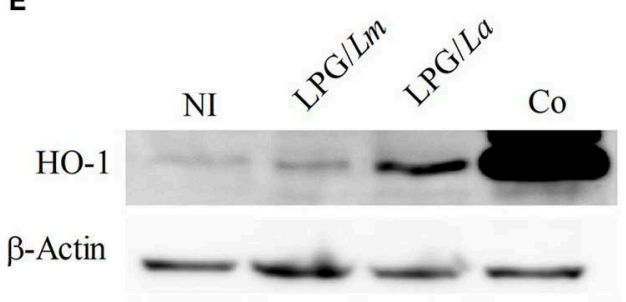

G

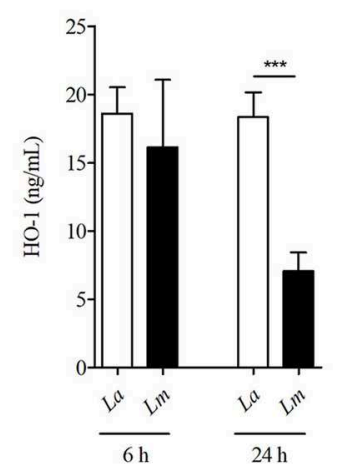

B

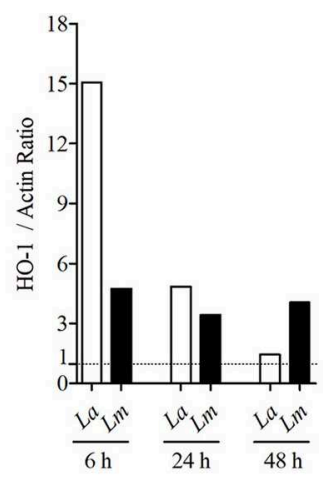

D

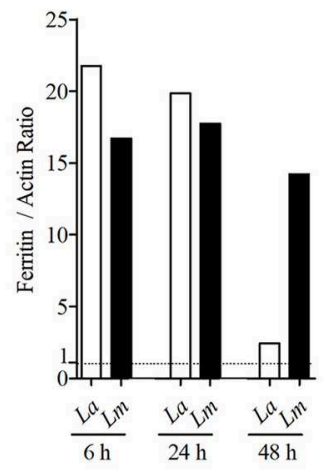

F

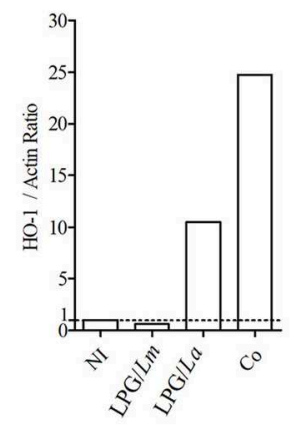

H

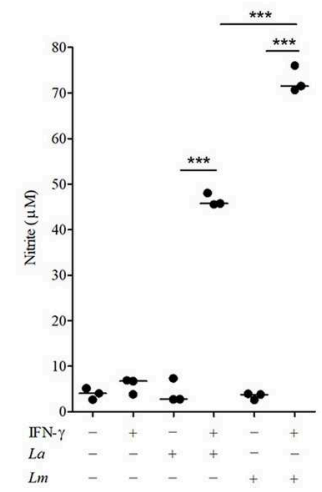

FIGURE 7 | Leishmania spp. infection modulates levels of HO-1, ferritin and NO production in CBA BMMØ. Effect of $L$. amazonensis and $L$. major infection on HO-1 and ferritin protein levels, as well as NO production. BMM $\varnothing$ were infected or not with $L$. amazonensis or $L$. major, or incubated with purified $L P G$ at $10 \mu \mathrm{g} / \mathrm{mL}$ from parasites from these species as described in Materials and Methods. (A,C,E) Cobalt protoporphyrin IX stimulation was used as positive control. Six or $24 \mathrm{~h}$ after infection, $\mathrm{M} \varnothing$ were washed to remove extracellular parasites and protein levels were quantified by Western blotting. Actin was used as a loading control. (B,D,F) HO-1/actin and ferritin/actin fold increase ratios in comparison to control levels (dashed line), as determined by densitometry. Results shown in (B,D,F) 
FIGURE 7 | are representative of three independent experiments. (G) Effect of L. amazonensis and L. major infection on HO-1 production by ELISA. Statistical differences were evaluated using the One-Way ANOVA Tukey's Multiple Comparison Test. ${ }^{* * *} p<0.0001$. Data are representative of means \pm SE from five experiments. (H) Effect of L. amazonensis and L. major infection on BMM $\varnothing$ NO production. Macrophage NO production was measured by detecting nitrite in culture supernatants. Statistical differences were evaluated using the Student's $t$-test. ${ }^{\star \star \star} p<0.0001$. Data are representative of means \pm SE three independent experiments.

\section{Functional Evaluation of Proteins Involved in Iron Metabolism}

Evidence has indicated a link between the modulation of proteins that participate in the metabolism of iron and susceptibility to Leishmania infection in several experimental models of leishmaniasis (34). Herein we found that two proteins involved in iron metabolism, HO-1 and ferritin, were differentially expressed by L. amazonensis- and L. major-infected BMM $\varnothing$. In light of this, the CBA mouse model was employed to further investigate the role played by iron metabolism elements in the inflammatory response to Leishmania infection.

Next, we attempted to assess whether other proteins than $\mathrm{HO}$ 1 and ferritin, which are also involved in iron metabolism, are differentially influencing L. amazonensis- and L. major infection of CBA ВMMФ. Using confocal microscopy, we found increased binding (Figures 8A,C) and greater uptake (Figures 8B,D) of fluorescent holoTf in L. amazonensis-infected $\mathrm{BMM} \Phi$. More interestingly, fluorescent-labeled holoTf was also detected at higher levels in the large parasitophorous vacuoles (Figure 8E) induced by L. amazonensis, in comparison to those found in the smaller vacuoles induced by L. major, for up to $24 \mathrm{~h}$ after infection. In sum, these findings indicate holoTf-mediated endocytosis was higher in the L. amazonensis-infected cells.

\section{DISCUSSION}

Advances in proteomics have greatly contributed to the identification of biological pathways, both in the parasite and host, allowing for a more global and integrated view of biological processes (4). In the field of Leishmania research, many proteomic studies have focused on a variety of aspects related to parasite biology and host interactions, such as parasite life-cycle, drug resistance mechanisms, identification of immunogenic proteins for vaccine development and the identification of targets for chemotherapeutic treatment, as well as biomarkers that hold potential for use in diagnosis (9-11, 35-39). However, the mechanisms involved in interactions between Leishmania parasites and the host, as well as the factors that drive disease outcome, warrant comprehensive investigation [revised by Veras et al. (6)].

Using a proteomic approach, the present study demonstrated that $L$. amazonensis and L. major modulate the expression of proteins differently in CBA MØ. A total of 2,838 proteins were initially identified in BMM $\varnothing$ using the SEQUEST algorithm. Data mining analyses and validation assays were then performed, and IPA was employed to perform biological enrichment analysis using the 15 datasets generated from allvs.-all comparisons of the experimental conditions. IPA revealed that NRF2 transcriptional factor signatures, present in one of the 4 CPs and one of the 7 UTFs, were strongly associated with Leishmania infection. In consonance, a recent study described that Leishmania induces NRF2 expression in M $\varnothing$ via protein kinase $\mathrm{R}$ in vitro, as well as in tissues of human cutaneous leishmaniasis. In addition, transcriptomic analysis highlighted the importance of NRF2 signaling in cutaneous leishmaniasis (22).

The Great Oxygenation Event (GOE) resulted in increased levels of $\mathrm{O}_{2}$, which oxidized ferrous iron $\left(\mathrm{Fe}^{2+}\right)$, thereby resulting in the rusting of the earth. The development of antistress systems was critical for reducing exposure to these toxic elements during early evolutionary development. Among these critical systems, the Kelch-like ECH-associated protein 1 (KEAP1)-NRF2 system emerges as one mainly responsible for antioxidant defenses, with NRF2 being the master transcription factor that possibly appeared around the time of the GOE (40). KEAP1-NRF2 is a delicate detoxification system in mammalian cells that exerts both cytoprotective and antioxidant functions, as well as deleterious effects by producing free radicals that can be regulated in several steps involved in iron metabolism $(15-17,41)$.

Cumulative evidence indicates that iron metabolism influences parasite survival within parasitophorous vacuoles (42, 43). Leishmania parasite-host cell interaction triggers a finely regulated response that can result in either a beneficial effect, iron acquisition and usage by Leishmania, which is essential to parasite multiplication, or can generate byproducts that accommodate reactive free radicals, which are toxic to intracellular parasites $(44,45) . \mathrm{NO}^{\bullet}$ is a known intracellular secondary messenger that can also react with superoxide anion $\left(\mathrm{O}^{--}\right)$to form peroxynitrite (ONOO-) by way of an enzymeindependent mechanism. ONOO- is a highly reactive molecule that interacts with most biologic molecules, including $\mathrm{Fe}-\mathrm{S}$ clusters, often causing reversible/irreversible cell damage (45). Previously, we also demonstrated that L. amazonensis-infected $\mathrm{M} \varnothing$ induced lower amounts of ROS in comparison with $L$. major (46). Herein, we showed that L. amazonensis-infected MØ produced lower levels of NO in comparison with L. major. Consistently with our results, NRF2-deficient MØ presented increased levels of ROS/RNS and reduced expression of Sod1, a NRF2-dependent gene, which resulted in reduced parasite load (22). Although these results reinforce the notion that NRF2 activation and translocation to the nucleus is associated with a reduced oxidative response in $L$. amazonensis infection, the mechanisms and metabolic processes involved in the growth and killing of the parasite are not similar to those involved in L. major. Thus, it is possible that factors other than oxidative response play an important role in Leishmania spp infection outcome. In the case of L. amazonensis, high expression of the tryparedoxin peroxidase isoform contributes to parasite ability to adapt to and antagonize the hostile microenvironment of macrophage-induced parasitophorous vacuoles, providing an alternative explanation for persistent infection in the mammalian host (47). 

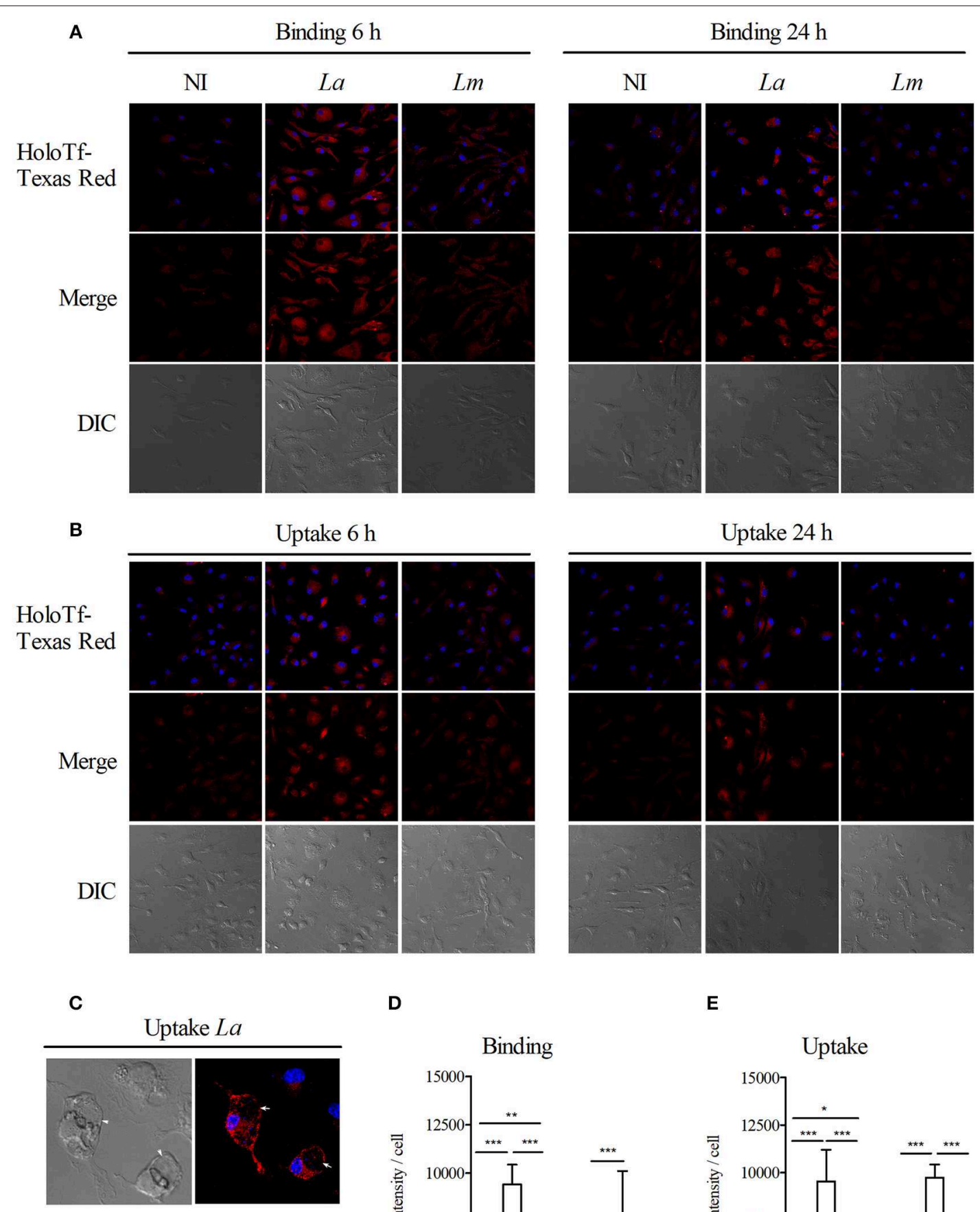

D

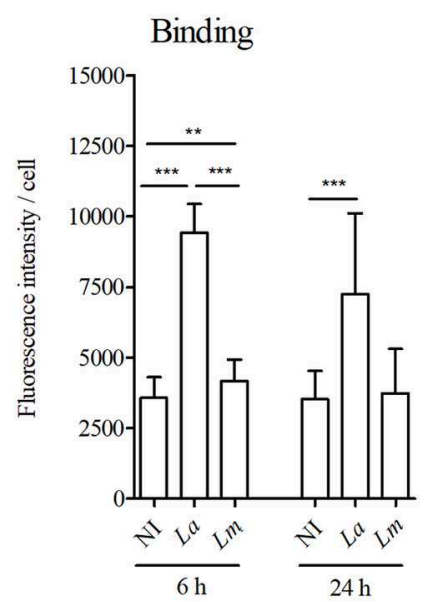

E

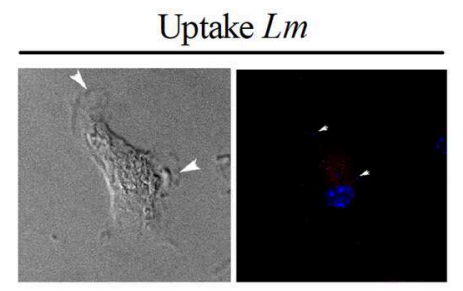

FIGURE 8 | L. amazonensis induces higher holoTf uptake than L. major in BMM $\varnothing$. BMM $\varnothing$ either uninfected, or infected with L. amazonensis or L. major for 6 or $24 \mathrm{~h}$ were incubated with (A) holoTf-Texas Red for 30 min at $4^{\circ} \mathrm{C}$ to allow binding or $(\mathbf{B})$ at $37^{\circ} \mathrm{C}$ to allow internalization, followed by reincubation for an additional 40 min in 
FIGURE 8 | holoTf-free medium and then analyzed by confocal microscopy. Fluorescence intensity from 30 cells from each group after binding (D) or internalization (E) of holoTf was quantified using ImageJ software. (C) Images illustrating L. amazonensis- and L. major-induced parasitophorous vacuoles labeled with holoTf. Statistical differences were evaluated using the Student's $t$-test $\left({ }^{\star} p<0.05,{ }^{\star \star} p<0.001,{ }^{\star \star \star} p<0.0001\right)$. Data are representative of three independent experiments.

Host $M \varnothing$ can regulate the production of deleterious iron byproducts generated from several steps of iron metabolism, together with the participation of some proteins, we found in the present study to be highly expressed by L. amazonensis-infected BMMØ. Studies have consistently shown that enhanced HO-1 expression is associated with increased parasite load, as well as the activation of an anti-inflammatory response in conjunction with reduced levels of inflammatory cytokines, such as TNF- $\alpha$ and IL12. These effects are orchestrated by Nrf2-promoter activation, which also results in increased levels of $\mathrm{Cu} / \mathrm{Zn}$ superoxide dismutase expression in human monocytes $(19,22,44)$. Previous study has shown that either parasites and its LPG induced HO-1 in $M \varnothing$ infected with the viscerotropic species L. infantum (19). Herein, we observed that higher levels of HO-1 was induced by L. amazonensis and its LPG compared to L. major. In accordance with these observations, it is possible that this different responses may be a result of LPG polymorphisms in those species (48-50). Further evidence presented herein links the involvement of the iron metabolism pathway with elevated HO-1 in L. amazonensisinfected cells. In addition, BMM $\varnothing$ incubated with L. amazonensis LPG were also shown to induce higher levels of HO-1 expression. Furthermore, the L. amazonensis-induced uptake of HoloTf in BMM $\varnothing$ was higher than that induced by L. major, and HoloTf was also detected at higher levels in vacuoles induced by $L$. amazonensis. These findings corroborate a previous study that showed holoTf-labeled endosomes preferentially fuse with $L$. amazonensis-induced parasitophorous vacuoles (51).

Altogether, in contrast to L. major-infected BMMØ, L. amazonensis-infected BMM $\varnothing$ exhibited increased expression of NRF2 and anti-oxidant HO-1, together with higher levels of holoTf in parasitophorous vacuoles, which may contribute to the persistence of Leishmania amazonensis infection. In this context, in addition to parasite factors, different protein signatures are triggered in CBA BMM $\varnothing$ in response to L. amazonensis and $L$. major infection, which could play a role in the outcome of distinct clinical forms of leishmaniasis.

\section{DATA AVAILABILITY}

The SEQUEST output file can be found in the Dryad Digital Repository: https://doi.org/10.5061/dryad.tr4185n.

\section{ETHICS STATEMENT}

The CBA mice used in the present study were provided by the animal care facility at the Gonçalo Moniz

\section{REFERENCES}

1. Lemos de Souza V, Ascencao Souza J, Correia Silva TM, Sampaio Tavares Veras P, Rodrigues de-Freitas LA. Different Leishmania species determine
Institute-Fiocruz-Bahia, following approval by the Institutional Animal Experimentation Review Board (CEUA) under protocol number 005/2014. Animals were kept and handled in accordance with the norms recommended by the International Guiding Principles for Biomedical Research Involving Animals; all experimental protocols complied with these guidelines, as well as all resolutions established by the Brazilian National Council for the Control of Animal Experimentation (CONCEA).

All protocols, analytic methods and material used in the present study are available upon request to all interested researchers.

\section{AUTHOR CONTRIBUTIONS}

JdM and PV conceived and designed the experiments. JdM, RK, $\mathrm{CO}, \mathrm{AP}, \mathrm{TdA}, \mathrm{FRLM}, \mathrm{AR}$, and AL performed and analyzed the proteomic experiments. NL, JL, ÁV, RS, UL, and VB performed and analyzed the validation experiments. JdM, RK, RS, GB, MK, FKM, UL, JR, VB, and PV contributed with reagents, materials, and analysis tools. JdM and PV wrote the manuscript. All authors contributed to manuscript elaboration and revision and approved the final version prior to submission.

\section{FUNDING}

This work was supported by grants from Fundação de Amparo à Pesquisa do Estado da Bahia (PV http://www.fapesb.ba.gov.br), Conselho Nacional de Pesquisa e Desenvolvimento Científico (PV http://www.cnpq.br) and National Institute of Science and Technology of Tropical Disease (PV http://inct.cnpq.br/ web/inct-dt). VB, PV, and UL are senior investigators funded by CNPq. The funders had no role in study design, data collection or analysis, the decision to publish, or preparation of the manuscript.

\section{ACKNOWLEDGMENTS}

The authors would like to thank Andris K. Walter for English language revision and manuscript copyediting assistance.

\section{SUPPLEMENTARY MATERIAL}

The Supplementary Material for this article can be found online at: https://www.frontiersin.org/articles/10.3389/fimmu. 2019.01362/full\#supplementary-material

distinct profiles of immune and histopathological responses in CBA mice. Microbes Infect. (2000) 2:1807-15. doi: 10.1016/S1286-4579(00)01340-X

2. Gomes IN, Calabrich AF, Tavares Rda S, Wietzerbin J, de Freitas LA, Veras PS. Differential properties of CBA/J mononuclear phagocytes recovered from 
an inflammatory site and probed with two different species of Leishmania. Microbes Infect. (2003) 5:251-60. doi: 10.1016/S1286-4579(03)00025-X

3. Gaudreau PO, Stagg J, Soulieres D, Saad F. The present and future of biomarkers in prostate cancer: proteomics, genomics, and immunology advancements. Biomark Cancer. (2016) 8:15-33. doi: 10.4137/BIC.S31802

4. Graves PR, Haystead TA. Molecular biologist's guide to proteomics. Microbiol Mol Biol Rev. (2002) 66:39-63. doi: 10.1128/MMBR.66.1.39-63.2002

5. Veras P, de Menezes J. Using proteomics to understand how leishmania parasites survive inside the host and establish infection. Int J Mol Sci. (2016) 17:1270. doi: $10.3390 /$ ijms 17081270

6. Veras PST, Ramos PIP, de Menezes JPB. In search of biomarkers for pathogenesis and control of leishmaniasis by global analyses of leishmania-infected macrophages. Front Cell Infect Microbiol. (2018) 8:326. doi: $10.3389 /$ fcimb.2018.00326

7. Bente M, Harder S, Wiesgigl M, Heukeshoven J, Gelhaus C, Krause E, et al. Developmentally induced changes of the proteome in the protozoan parasite Leishmania donovani. Proteomics. (2003) 3:1811-29. doi: 10.1002/pmic.200300462

8. Biyani N, Madhubala R. Quantitative proteomic profiling of the promastigotes and the intracellular amastigotes of Leishmania donovani isolates identifies novel proteins having a role in Leishmania differentiation and intracellular survival. Biochim Biophys Acta. (2012) 1824:1342-50. doi: 10.1016/j.bbapap.2012.07.010

9. El Fakhry Y, Ouellette M, Papadopoulou B. A proteomic approach to identify developmentally regulated proteins in Leishmania infantum. Proteomics. (2002) 2:1007-17. doi: 10.1002/1615-9861(200208)2:8\&lt;1007::AIDPROT1007\&gt;3.0.CO;2-G

10. Morales MA, Watanabe R, Laurent C, Lenormand P, Rousselle JC, Namane A, et al. Phosphoproteomic analysis of Leishmania donovani pro- and amastigote stages. Proteomics. (2008) 8:350-63. doi: 10.1002/pmic.200700697

11. Menezes JP, Almeida TF, Petersen AL, Guedes CE, Mota MS, Lima JG, et al. Proteomic analysis reveals differentially expressed proteins in macrophages infected with Leishmania amazonensis or Leishmania major. Microbes Infect. (2013) 15:579-91. doi: 10.1016/j.micinf.2013.04.005

12. Singh AK, Pandey RK, Siqueira-Neto JL, Kwon YJ, Freitas-Junior LH, Shaha $\mathrm{C}$, et al. Proteomic-based approach to gain insight into reprogramming of THP-1 cells exposed to Leishmania donovani over an early temporal window. Infect Immun. (2015) 83:1853-68. doi: 10.1128/IAI.02833-14

13. Costa MM, Andrade HM, Bartholomeu DC, Freitas LM, Pires SF, Chapeaurouge AD, et al. Analysis of Leishmania chagasi by 2-D difference gel electrophoresis (2-D DIGE) and immunoproteomic: identification of novel candidate antigens for diagnostic tests and vaccine. J Proteome Res. (2011) 10:2172-84. doi: 10.1021/pr101286y

14. Loboda A, Damulewicz M, Pyza E, Jozkowicz A, Dulak J. Role of Nrf2/HO1 system in development, oxidative stress response and diseases: an evolutionarily conserved mechanism. Cell Mol Life Sci. (2016) 73:3221-47. doi: 10.1007/s00018-016-2223-0

15. Kensler TW, Wakabayashi N, Biswal S. Cell survival responses to environmental stresses via the Keap1-Nrf2-ARE pathway. Annu Rev Pharmacol Toxicol. (2007) 47:89-116. doi: 10.1146/annurev.pharmtox.46.120604.141046

16. Mitsuishi $\mathrm{Y}$, Motohashi H, Yamamoto M. The Keap1-Nrf2 system in cancers: stress response and anabolic metabolism. Front Oncol. (2012) 2:200. doi: $10.3389 /$ fonc. 2012.00200

17. Kerins M, Ooi A. The roles of NRF2 in modulating cellular iron homeostasis. Antioxid Redox Signal. (2017) 29:1756-73. doi: 10.1089/ars.2017.7176

18. Andrade BB, Araujo-Santos T, Luz NF, Khouri R, Bozza MT, Camargo $\mathrm{LM}$, et al. Heme impairs prostaglandin $\mathrm{E} 2$ and TGF-beta production by human mononuclear cells via $\mathrm{Cu} / \mathrm{Zn}$ superoxide dismutase: insight into the pathogenesis of severe malaria. J Immunol. (2010) 185:1196-204. doi: 10.4049/jimmunol.0904179

19. Luz NF, Andrade BB, Feijó DF, Araújo-Santos T, Carvalho GQ, Andrade $\mathrm{D}$, et al. Heme oxygenase-1 promotes the persistence of Leishmania chagasi Infection. J Immunol. (2012) 188:4460-7. doi: 10.4049/jimmunol.1103072

20. Marver HS, Schmid R, Schutzel H. Heme and methemoglobin: naturally occurring repressors of microsomal cytochrome. Biochem Biophys Res Commun. (1968) 33:969-74. doi: 10.1016/0006-291X(68)90408-7
21. Wagener FA, Volk HD, Willis D, Abraham NG, Soares MP, Adema GJ, et al. Different faces of the heme-heme oxygenase system in inflammation. Pharmacol Rev. (2003) 55:551-71. doi: 10.1124/pr.55.3.5

22. de Vivarini Á, Calegari-Silva T, Saliba A, Boaventura V, França-Costa J, Khouri R, et al. Systems approach reveals nuclear factor erythroid 2-related factor 2/protein kinase R crosstalk in human cutaneous leishmaniasis. Front Immunol. (2017) 8:1127. doi: 10.3389/fimmu.2017.01127

23. Cassat JE, Skaar EP. Iron in infection and immunity. Cell Host Microbe. (2013) 13:509-19. doi: 10.1016/j.chom.2013.04.010

24. Nairz M, Schroll A, Sonnweber T, Weiss G. The struggle for iron - a metal at the host-pathogen interface. Cell Microbiol. (2010) 12:1691-702. doi: $10.1111 / j .1462-5822.2010 .01529 . x$

25. Schaible UE, Kaufmann SH. Iron and microbial infection. Nat Rev Microbiol. (2004) 2:946-53. doi: 10.1038/nrmicro1046

26. Taylor MC, Kelly JM. Iron metabolism in trypanosomatids, and its crucial role in infection. Parasitology. (2010) 137:899-917. doi: 10.1017/S0031182009991880

27. Papanikolaou G, Pantopoulos K. Iron metabolism and toxicity. Toxicol Appl Pharmacol. (2005) 202:199-211. doi: 10.1016/j.taap.2004.06.021

28. Koskenkorva-Frank TS, Weiss G, Koppenol WH, Burckhardt S. The complex interplay of iron metabolism, reactive oxygen species, and reactive nitrogen species: insights into the potential of various iron therapies to induce oxidative and nitrosative stress. Free Radic Biol Med. (2013) 65:1174-94. doi: 10.1016/j.freeradbiomed.2013.09.001

29. Esposito BP, Breuer W, Sirankapracha P, Pootrakul P, Hershko C, Cabantchik ZI. Labile plasma iron in iron overload: redox activity and susceptibility to chelation. Blood. (2003) 102:2670-7. doi: 10.1182/blood-2003-03-0807

30. Mastroeni P, Vazquez-Torres A, Fang FC, Xu Y, Khan S, Hormaeche CE, et al. Antimicrobial actions of the NADPH phagocyte oxidase and inducible nitric oxide synthase in experimental salmonellosis. II Effects on microbial proliferation and host survival in vivo. J Exp Med. (2000) 192:237-48. doi: 10.1084/jem.192.2.237

31. Nairz M, Haschka D, Demetz E, Weiss G. Iron at the interface of immunity and infection. Front Pharmacol. (2014) 5:152. doi: 10.3389/fphar.2014.00152

32. Huynh C, Sacks DL, Andrews NW. A Leishmania amazonensis ZIP family iron transporter is essential for parasite replication within macrophage phagolysosomes. J Exp Med. (2006) 203:2363-75. doi: 10.1084/jem.20060559

33. Nogueira PM, Assis RR, Torrecilhas AC, Saraiva EM, Pessoa NL, Campos MA, et al. Lipophosphoglycans from Leishmania amazonensis strains display immunomodulatory properties via TLR4 and do not affect sand fly infection. PLoS Negl Trop Dis. 10:e0004848. doi: 10.1371/journal.pntd.0004848

34. Silva-Gomes S, Vale-Costa S, Appelberg R, Gomes MS. Iron in intracellular infection: to provide or to deprive? Front Cell Infect Microbiol. (2013) 3:96. doi: 10.3389/fcimb.2013.00096

35. Drummelsmith J, Brochu V, Girard I, Messier N, Ouellette M. Proteome mapping of the protozoan parasite Leishmania and application to the study of drug targets and resistance mechanisms. Mol Cell Proteomics. (2003) 2:146-55. doi: 10.1074/mcp.M200085-MCP200

36. Forgber M, Basu R, Roychoudhury K, Theinert S, Roy S, Sundar S, et al. Mapping the antigenicity of the parasites in Leishmania donovani infection by proteome serology. PLoS ONE. 1:e40. doi: 10.1371/journal.pone.0000040

37. Gupta SK, Sisodia BS, Sinha S, Hajela K, Naik S, Shasany AK, et al. Proteomic approach for identification and characterization of novel immunostimulatory proteins from soluble antigens of Leishmania donovani promastigotes. Proteomics. (2007) 7:816-23. doi: 10.1002/pmic.200600725

38. Paape D, Lippuner C, Schmid M, Ackermann R, Barrios-Llerena ME, ZimnyArndt U, et al. Transgenic, fluorescent Leishmania mexicana allow direct analysis of the proteome of intracellular amastigotes. Mol Cell Proteomics. (2008) 7:1688-701. doi: 10.1074/mcp.M700343-MCP200

39. Rosenzweig D, Smith D, Opperdoes F, Stern S, Olafson RW, Zilberstein D. Retooling Leishmania metabolism: from sand fly gut to human macrophage. FASEB J. (2008) 22:590-602. doi: 10.1096/fj.07-9254com

40. Gacesa R, Dunlap WC, Barlow DJ, Laskowski RA, Long PF. Rising levels of atmospheric oxygen and evolution of Nrf2. Sci Rep. 6:27740. doi: 10.1038/srep27740

41. Singh N, Ahmad Z, Baid N, Kumar A. Host heme oxygenase-1: friend or foe in tackling pathogens? IUBMB Life. (2018) 70:869-80. doi: 10.1002/iub.1868 
42. Marx JJM. Iron and infection: competition between host and microbes for a precious element. Best Pract Res Clin Haematol. (2002) 15:411-26. doi: 10.1016/S1521-6926(02)90001-0

43. Mittra B, Andrews NW. IRONy OF FATE: role of iron-mediated ROS in Leishmania differentiation. Trends Parasitol. (2013) 29:489-96. doi: 10.1016/j.pt.2013.07.007

44. Saha S, Basu M, Guin S, Gupta P, Mitterstiller A-M, Weiss G, et al. Leishmania donovani exploits macrophage heme oxygenase-1 to neutralize oxidative burst and TLR signaling-dependent host defense. J Immunol. (2018) 202:827-40. doi: 10.4049/jimmunol.1800958

45. Zaidi A, Singh K, Ali V. Leishmania and its quest for iron: an update and overview. Mol Biochem Parasitol. (2017) 211:15-25. doi: 10.1016/j.molbiopara.2016.12.004

46. Almeida TF, Palma LC, Mendez LC, Noronha-Dutra AA, Veras PS. Leishmania amazonensis fails to induce the release of reactive oxygen intermediates by CBA macrophages. Parasite Immunol. (2012) 34:492-8. doi: 10.1111/j.1365-3024.2012.01384.x

47. Henard CA, Carlsen ED, Hay C, Kima PE, Soong L. Leishmania amazonensis amastigotes highly express a tryparedoxin peroxidase isoform that increases parasite resistance to macrophage antimicrobial defenses and fosters parasite virulence. PLoS Negl Trop Dis. 8:e3000. doi: 10.1371/journal.pntd. 0003000

48. McConville MJ, Homans SW. Identification of the defect in lipophosphoglycan biosynthesis in a non-pathogenic strain of Leishmania major. J Biol Chem. (1992) 267:5855-61.
49. McConville MJ, Turco SJ, Ferguson MA, Sacks DL. Developmental modification of lipophosphoglycan during the differentiation of Leishmania major promastigotes to an infectious stage. EMBO J. (1992) 11:3593-600. doi: 10.1002/j.1460-2075.1992.tb05443.x

50. Nogueira PM, Guimaraes AC, Assis RR, Sadlova J, Myskova J, Pruzinova K, et al. Lipophosphoglycan polymorphisms do not affect Leishmania amazonensis development in the permissive vectors Lutzomyia migonei and Lutzomyia longipalpis. Parasit Vectors. 10:608. doi: 10.1186/s13071-017-2568-8

51. Borges VM, Vannier-Santos MA, de Souza W. Subverted transferrin trafficking in Leishmania-infected macrophages. Parasitol Res. (1998) 84:81122. doi: $10.1007 / \mathrm{s} 004360050493$

Conflict of Interest Statement: The authors declare that the research was conducted in the absence of any commercial or financial relationships that could be construed as a potential conflict of interest.

Copyright (c) 2019 de Menezes, Khouri, Oliveira, Petersen, de Almeida, Mendes, Rebouças, Lorentz, Luz, Lima, Ramos, Soares, Rugani, Buck, Krieger, Marchini, Vivarini, Lopes, Borges and Veras. This is an open-access article distributed under the terms of the Creative Commons Attribution License (CC BY). The use, distribution or reproduction in other forums is permitted, provided the original author(s) and the copyright owner(s) are credited and that the original publication in this journal is cited, in accordance with accepted academic practice. No use, distribution or reproduction is permitted which does not comply with these terms. 